\title{
Summer Drought Patterns in the Middle-Lower Reaches of the Yangtze River Basin and Their Connections with Atmospheric Circulation before and after 1980
}

\author{
Shuping Li, ${ }^{1}$ Guolin Feng, ${ }^{1,2,3}$ and Wei Hou ${ }^{2}$ \\ ${ }^{1}$ College of Atmospheric Sciences, Lanzhou University, Lanzhou 730000, China \\ ${ }^{2}$ National Climate Center, China Meteorological Administration, Beijing 100081, China \\ ${ }^{3}$ College of Physical Science and Technology, Yangzhou University, Yangzhou 225000, China \\ Correspondence should be addressed to Wei Hou; houwei@cma.gov.cn
}

Received 25 August 2016; Revised 19 November 2016; Accepted 7 December 2016

Academic Editor: Jorge E. Gonzalez

Copyright (C) 2016 Shuping Li et al. This is an open access article distributed under the Creative Commons Attribution License, which permits unrestricted use, distribution, and reproduction in any medium, provided the original work is properly cited.

\begin{abstract}
The three summer drought patterns of the middle-lower reaches of the Yangtze River basin (MLRYRB) and their associated atmospheric circulation were investigated before and after 1980. For the whole-basin wide drought pattern during 1961-1979, the anomalous high ridge over Japan blocked the northerly flow from Siberia to southern China. Further, the western Pacific subtropical high (WPSH) was weaker than normal and shifted eastward. For the southern drought and northern flood pattern during 1961-1979, the zonal circulation was straight and an anomalous anticyclonic circulation was located over Japan. Less moisture was transported to southern China associated with the weakened WPSH. During 1980-2013, the WPSH extended westward and controlled the southern part of the MLRYRB, and an anomalous cyclonic circulation was centered over Japan. For the southern flood and northern drought pattern during 1961-1979, the meridional circulation was obvious, and the WPSH was weaker than normal. The anomalous southwesterly moisture transport appeared to southern China. However, during 1980-2013 the continental high pressure impacted northern China. The WPSH shifted eastward and the anomalous northeasterly moisture transport presented over eastern China.
\end{abstract}

\section{Introduction}

In recent years, extreme weather and climate events have increased in number and intensity in many parts of the world $[1,2]$. Drought has become one of the most complex weatherrelated disasters [3-5] and has a severe impact on agriculture, water resources, economy, and society. The duration and occurrence of drought show an increasing tendency with the global warming $[6,7]$, which has been questioned by others $[8,9]$. Despite the uncertainty over recent trends, it is accepted widely that drought occurrence is probably increased by a less intense hydrological cycle under climate change $[10,11]$. The hydrologic cycle strength is defined as the global mean precipitation, and an increase in the strength means a precipitation increase and hence a runoff increase. The response of hydrologic cycle to warming is less rainfall, resulting in more intense drought [12]. Given the probability of increased drought, improved detection and prediction of drought onset are vital. Much effort has also been made to detect the relationship between atmospheric circulation and drought occurrence over different regions $[13,14]$. Researchers have investigated the role of atmospheric circulation patterns, such as the North Atlantic Oscillation and eastern Atlantic/western Russia patterns [15, 16].

The drought variability in China, especially the regional drought, has attracted more attention from the meteorologists [17-19]. The middle-lower reaches of the Yangtze River basin (MLRYRB) have a large population and are an economic center of national significance. Much attention has been given to identify the changes of precipitation/drought over the MLRYRB [20, 21]. Specifically, it was well known that the Pacific basin sea surface temperature (SST) had experienced a great climate shift in the late 1970s [22, 23]. Gong and Ho [24] indicated that summer rainfall shift over the Yangtze River valley in the late 1970s is associated with the enlarged and intensified western Pacific subtropical high 
(WPSH). Since the late 1970s, the WPSH has extended westward, which has resulted in excessive rainfall along the middle and lower reaches of the Yangtze River valley and deficient rainfall over north China [25]. Summer drought patterns associated with the westward shift of the WPSH in the late 1970s remain unresolved. Some statistical analyses have investigated the summer drought/precipitation patterns and their corresponding atmospheric circulation. Wang et al. [26] indicated that three leading modes of precipitation during June-July over the Jiang-Huai basin are the whole Jiang-Huai basin mode, north-south dipole mode, and eastwest dipole mode for 1958-1999 and investigated their corresponding atmospheric circulation using composite analysis. However, the influence of the climate shift in the late 1970s on atmospheric circulation is not considered. Recent studies [27-29] suggested that since the late 1970s the climate shift led to a significant atmospheric circulation change over various regions of the globe, including East Asia. Although the aforementioned studies already investigate the atmospheric circulation differences associated with the climate shift in the late 1970s or drought/precipitation patterns over the MLRYRB or whole eastern China, to authors' knowledge there are not recent studies that deal with the connections between summer drought patterns over the MLRYRB and atmospheric circulation before and after the late 1970s, respectively. Given the above research gaps, it is essential to consider the influence of the climate shift in the late 1970s on large-scale atmospheric circulation when attempting to investigate summer drought over the MLRYRB and its associated atmospheric circulation.

Generally, meteorological drought is characterized by months to years of precipitation deficit, suggesting that precipitation is the dominant factor controlling drought. The WPSH and South Asian high (SAH), which are two members of East Asian summer monsoon system circulation, contribute to the summer precipitation distribution in China [30, 31]. The seasonal variation of WPSH is closely related to the onset and withdrawal of East Asian summer monsoon, and the abrupt northward movement of WPSH is accompanied with abrupt changes in the circulation patterns over eastern Asia [32]. Since the WPSH extends westward, an anomalous anticyclone in the lower level occupies East Asia and its coast; thus the above-normal monsoonal southwesterlies, originated from the South China Sea (SCS) and western Pacific Ocean, lands on eastern China. Associated with a large distance northeastward retreat of the WPSH, strong southwesterly moisture from the Bay of Bengal is transported to the SCS-Philippine Sea, resulting in weak moist monsoon flow toward eastern China [33]. Furthermore, the summer precipitation over the MLRYRB is also closely related to the Okhotsk high ridge in summer [34]. Tao and Xu [35] pointed out that because the westward-extended WPSH occupies the continent or due to the appearance of isolated continental subtropical high centers, the Yangtze and Huaihe River basins are prone to suffer persistent drought. The moisture transport over the MLRYRB is associated with the advance and retreat of East Asian summer monsoon [36]. Zhang et al. [37] indicated that the decreasing strength of East Asian summer monsoon and increasing geopotential height (GPH) in north
China, South China Sea, and western Pacific regions are negatively connected with the northward propagation of the water vapor, favoring more precipitation in the MLRYRB. The relationship between atmospheric circulation and precipitation/drought over the MLRYRB has attracted much discussion, yet it remains a controversial issue. The abovementioned studies show that the drought/precipitation in the MLRYRB presents obvious variations and is closely related to atmospheric circulation; however, since the time scale of drought is different from that of precipitation, this paper mainly investigates the summer drought patterns of the MLRYRB and their associated atmospheric circulation.

This paper takes into account the influence of the climate shift in the late 1970s on large-scale atmospheric circulation and focuses on the three summer drought patterns of the MLRYRB characterized by Standardized Precipitation Index (SPI) and their connections with large-scale atmospheric circulation. Despite the climate shift changepoint is a controversial issue, it seems widely accepted that the changepoint of the climate shift occurred in 1976/1977 or 1978/1979 [3840]. Therefore, we separate the whole period 1961-2013 into 1961-1979 and 1980-2013, and we mainly investigate the connections between the three summer drought patterns of the MLRYRB and atmospheric circulation in the selected time periods. The main goals of this paper are (1) to describe the leading modes of meteorological drought variability over the MLRYRB; (2) to identify the correlation between the leading modes of drought variability over the MLRYRB and largescale atmospheric circulation for 1961-1979 and 1980-2013, respectively; and (3) to investigate the similarities/differences of atmospheric circulation for the selected typical drought years corresponding to summer drought patterns of the MLRYRB. The correlation analysis provides a more detailed linkage between summer drought patterns of the MLRYRB and large-scale atmospheric circulation.

The remaining parts of this paper are organized as follows. Section 2 describes the datasets and the methods employed in this study. Section 3 depicts summer drought variability over the MLRYRB. In Section 3, we also identify the correlation between the leading modes of summer drought variability over the MLRYRB and atmospheric circulation during 19611979 and 1980-2013, respectively. We investigate the similarities/differences of atmospheric circulation for the selected typical drought years corresponding to summer drought patterns of the MLRYRB in Section 4. The conclusions and discussion of this study are presented in Section 5.

\section{Data and Methods}

Monthly GPH data during 1961-2013 is provided by the National Center for Environmental Prediction and National Center for Atmospheric Research (NCEP/NCAR), which has a horizontal resolution of $2.5^{\circ} \times 2.5^{\circ}$ [41]. Monthly precipitation data during 1961-2013 at 353 stations over the MLRYRB is provided by the National Meteorological Information Center of China Meteorological Administration, from which the Standardized Precipitation Index (SPI) is calculated to monitor and quantify drought. Our research area is the MLRYRB, including the Hubei, Hunan, Anhui, 


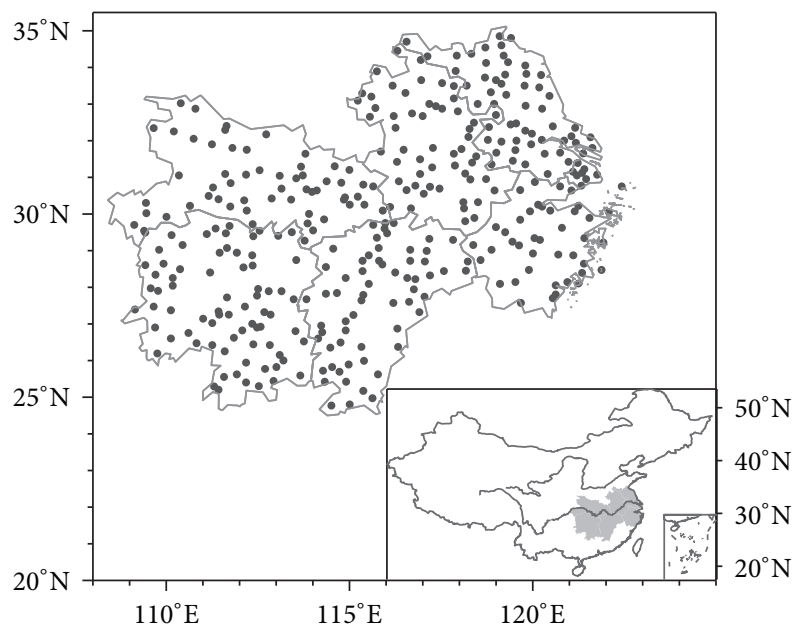

FIgURE 1: The spatial distribution of 353 stations over the middlelower reaches of the Yangtze River basin (MLRYRB); the shading area is the location of the MLRYRB.

Jiangsu, Jiangxi, and Zhejiang provinces, as well as Shanghai (Figure 1). The main study period is 1961-2013. Summer mean refers to the average of June, July, and August, and its anomalies are computed relative to the climatology of 19712000.

SPI is a meteorological drought index developed by Mckee et al. [42] for quantifying precipitation deficit at multiple time scales. The long-term precipitation data is fitted with a gamma distribution, and the cumulative probability of precipitation record for different time scales could be calculated. The value of SPI can be obtained by translation of cumulative probability into the standard normal random variable with mean of zero and variance of one. Since the SPI is calculated at various time scales (from 1 to $n$ months), it can be used for quantifying different types of drought events. The SPI depends only on precipitation and eliminates the influence of topography; therefore, it can also be used for different regions [43-45]. The SPI can be used to describe regional meteorological, agricultural, and hydrological drought conditions and is suitable for both dry and rainy seasons [46]. The Palmer Drought Severity Index (PDSI) is a hydrological drought index, which is based on precipitation and potential evaporation in combination with a simplistic soil moisture routine [47]. The main disadvantage of the PDSI is that it has fixed time scale but it is difficult to apply across different regions. The Standardized Precipitation-Evapotranspiration Index (SPEI) takes into account both the precipitation and evapotranspiration and can be calculated on time scales from 1 to 48 months [48]. SPEI is formulated following the same statistical method as the SPI; but it is based on climatic water balance, defined as precipitation minus potential evapotranspiration [49]. By calculating accumulated climatic water balance deficit, the SPEI may also provide information on soil moisture and hydrological droughts. However, we focus on the meteorological drought and do not consider the influence of atmospheric circulation on potential evapotranspiration. Hence, SPEI is not used in this article. In particular, SPI only focuses on precipitation and can be applied across different regions. Additionally, SPI can properly monitor and quantify drought in an easier way. Positive SPI values indicate wet conditions, while negative SPI values indicate dry conditions. In this article, an SPI for a 3-month time scale for the month of August (SPI3; hereafter) is used to quantity summer drought and implies that on the computation we take it into account, by default, as well as the precipitation from June and July.

The Empirical Orthogonal Function (EOF) technique decomposes the variance with the members being orthogonal to one another. The EOF modes form the most efficient basic set for the variance decomposition of a given dataset, and the EOF decomposition is an efficient method to investigate the spatial and temporal variability of time series field. Yet, the spatial structures associated with drought patterns vary from event to event, so that individual EOF modes could not explain all of the variance in given phenomena. Since observed phenomena are not strictly orthogonal, many authors rotate EOF modes in an attempt to extract more of signals associated with individual phenomena. However, rotation does not generate new signal [50]. The Rotated Empirical Orthogonal Function technique has been applied to the raw SPI3 from 1961 to 2013 at 353 stations over the MLYRYB, and similar results have been obtained. We have slightly changed the domain prescribed for the EOF analysis [e.g., $109-122^{\circ} \mathrm{E}, 25-35^{\circ} \mathrm{N}$ ] and also obtained similar results. Therefore, the present results are not sensitive to the choice of domain or decomposition methods.

The moving $t$-test (MTT) is employed to detect the abrupt changepoints of the decadal variation of summer drought patterns over the MLRYRB. For example, if the abrupt changepoint of a time series detected by MTT is 1991, this implies that its variation occurs in the period of 1990/1991. The abrupt changepoint of a time series, as detected by the MTT with a 9-year moving window, is the year with the most statistical significance and is significant at 99\% confidence level. In addition, the linear trends of GPH data are removed using linear least squares regression. The Mann-Kendall (MK) trend test is used to quantify statistical significance of the trend $[51,52]$, and statistical significance of the correlation coefficients is assessed at $90 \%$ confidence level using two-tailed Student's $t$-test.

\section{Summer Drought Patterns and Their Relationship with Atmospheric Circulation for the Periods 1961-1979 and 1980-2013}

3.1. The Three Summer Drought Patterns. The EOF technique is applied to the raw SPI3 from 1961 to 2013 at 353 stations over the MLRYRB. The first two leading EOF modes account for $24 \%$ and $17 \%$ of the total variance, respectively, and pass North's significance test [53]. For the third EOF mode, it is represents only $8.5 \%$ overall and does not pass North's significance test. Although the fourth EOF mode passes the significance test, it only accounts for $7.2 \%$ of the total variance. In fact, the first two EOF modes can well capture the characteristics of summer drought over the MLRYRB; therefore, the other EOF modes are not considered in this article. 


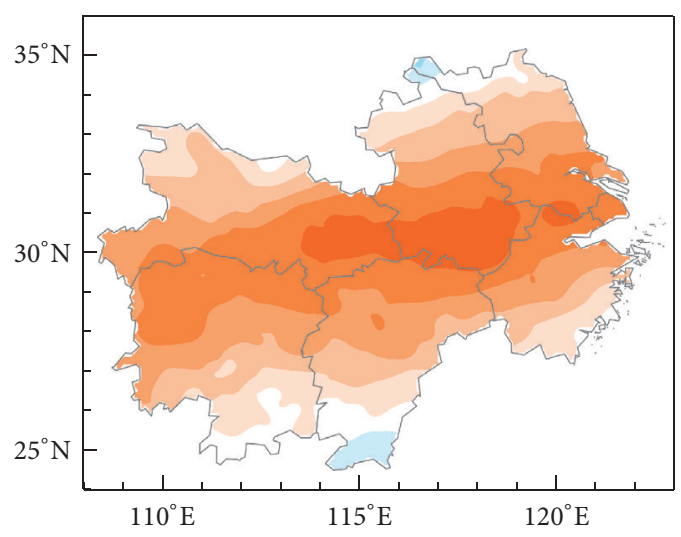

(a)

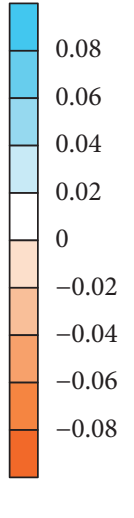

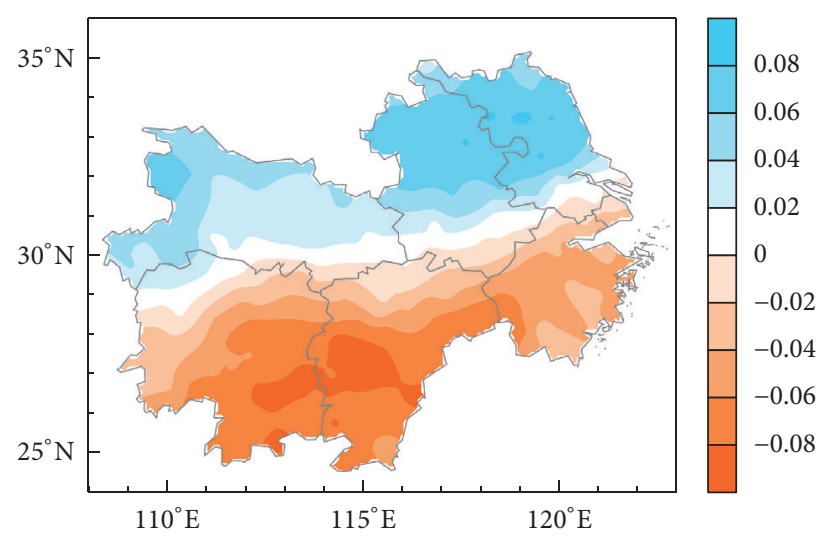

(b)

FIgUre 2: The distribution of the first two Empirical Orthogonal Function (EOF) modes of the Standardized Precipitation Index (SPI) for a 3-month time scale (SPI3) in August, derived for the period 1961-2013: (a) EOF1, (b) EOF2.

The first EOF mode is characterized by in-phase changes across whole region (Figure 2(a)). We refer to this mode as whole basin-wide drought pattern (WBWD) or whole basinwide flood pattern. The second EOF mode shows an out-ofphase pattern between the areas north and south about $30^{\circ} \mathrm{N}$ (Figure 2(b)). Here we refer to this mode as the southern drought and northern flood pattern (SDNF) or southern flood and northern drought (SFND). The two EOF modes are consistent with the previous research investigated by Wang et al. [26]. Based on the above-mentioned two EOF modes of SPI3, summer drought of the MLRYRB can be characterized by three distribution patterns: the WBWD pattern which refers to dry conditions across whole MLRYRB; the SDNF pattern which refers to the fact that dry conditions occur in the southern part of the MLRYRB accompanied by wet conditions in the northern part of the MLRYRB; and the SFND pattern which indicates wet conditions in the southern part of the MLRYRB with dry conditions in the northern part of the MLRYRB.

The PCs (hereafter, referred to PC1 and PC2) are normalized by their corresponding standard deviation (Figures 3(a) and 3(b)). The PC1 indicates a descending trend using least squares linear regression statistical method. The trend of $\mathrm{PCl}$ is significant at $95 \%$ confidence level according to MK trend test. The results suggest that more region-wide drought events occurred during the period 1961-1979, and more region-wide flood events appeared during the period 1980-2013 (Figure 3(a)). The PC2 of SPI3 shows distinct decadal variations. The changepoints of decadal variations of PC2 time series of coefficients detected by MTT are 1991 and 2002 (Figure 3(c)). The SDNF pattern likely occurred for the periods 1961-1991 and 2003-2013, whereas the SFND pattern much probably happened for the period 1992-2002. Particularly, the PC1 of SPI3 has no significant changepoints (Figure 3(c)).

In this study, we take into account the influence of the climate shift in the late 1970s on atmospheric circulation and its connection with the three summer drought patterns. In particular, the Pacific Decadal Oscillation (PDO) phase also changes from cool to warm in the late 1970s. Qian et al. [54] investigated decadal summer drought in eastern China and its linkage to the PDO and Atlantic Multidecadal Oscillation (AMO). To identify the relationship of the summer drought patterns over the MLRYRB with summer PDO and AMO, we investigate the correlation coefficients of the PCs with the summer time series of PDO and AMO for the periods 1961-2013, 1961-1979, and 1980-2013 (Table 1). The PC1 time series of coefficients is negatively correlated with the summer time series of PDO $(r=-0.27$, significant at $90 \%$ confidence level) and with the summer time series of AMO ( $r=$ -0.34 , significant at 95\% confidence level) for 1961-2013. However, the time series of $\mathrm{PCl}$ is not significantly correlated with summer PDO and AMO for 1961-1979 and 1980-2013. The time series of PC2 is not significantly correlated with summer PDO and AMO for 1961-2013, 1961-1979, and 19802013. These results indicate that the summer AMO and PDO are associated with long-term dry-wet variations in the MLRYRB.

For a WBWD year, if its $\mathrm{PC} 1$ is greater than 1.0 as well as absolute PC2, it is classified as positive phase of the first EOF mode. For a SDNF year, if its PC2 is greater than 1.0 as well as absolute PC1, it is classified as positive phase of the second EOF mode. For a SFND year, if its PC2 is less than -1.0 and the absolute PC2 is greater than the absolute $\mathrm{PCl}$, it is classified as negative phase of the second EOF mode. The WBWD years are 1961, 1966, 1967, 1968, 1972, 1978, and 1985. The SDNF years are 1963, 1965, 1971, 1991, 2003, and 2005. The SFND years are 1973, 1976, 1994, 1997, 2001, and 2003. The PC1 and PC2 values are shown as scatter diagrams for each year in Figure 3(d), with the WBWD years colored in red, SDNF years in blue, and SFND years in green. To further identify whether there are discernable changes of the relationship between summer drought patterns of the MLRYRB and atmospheric circulation for the periods 1961-1979 and 1980-2013, we selected four strongest WBWD, four strongest SDNF, and four strongest SFND years (Table 2). Specifically, we selected the two strongest SDNF (SFND) years during 1961-1979 and 1980-2013, respectively. 


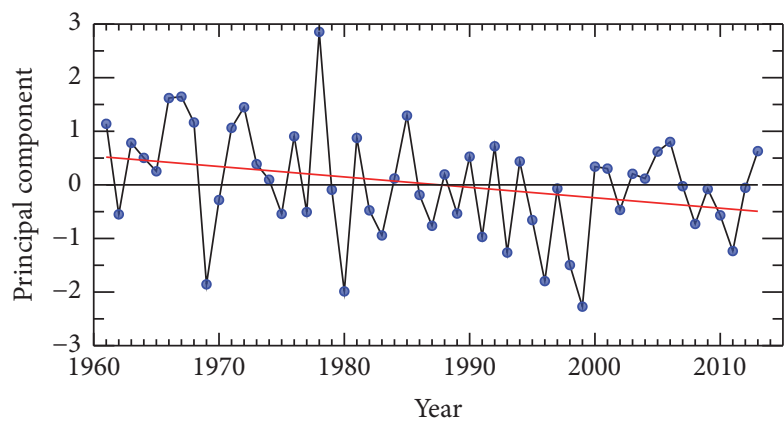

(a)

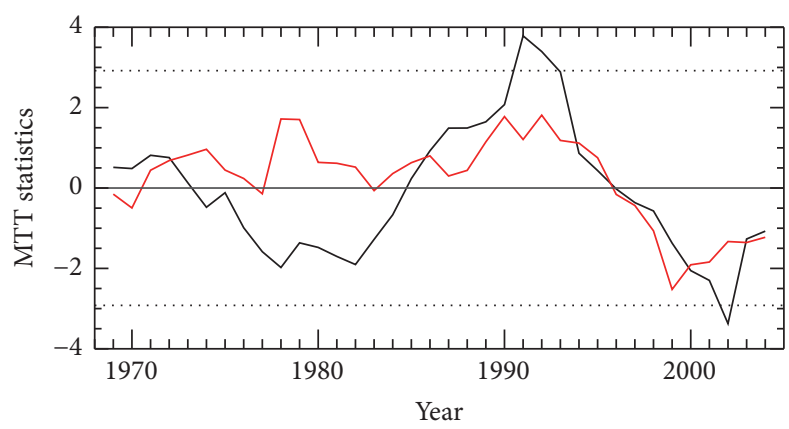

(c)

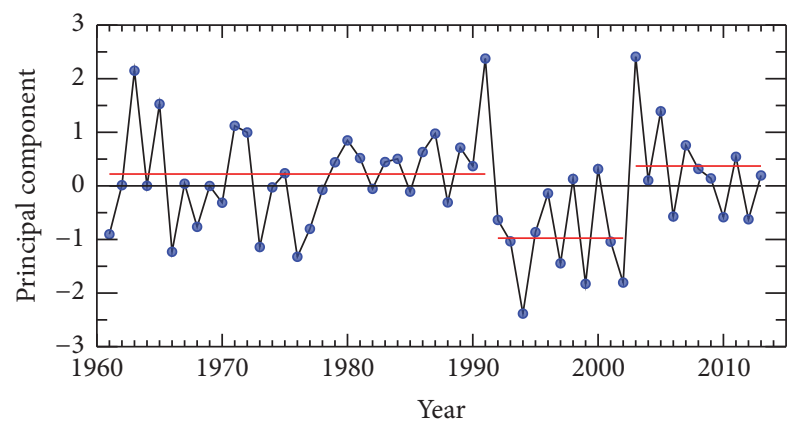

(b)

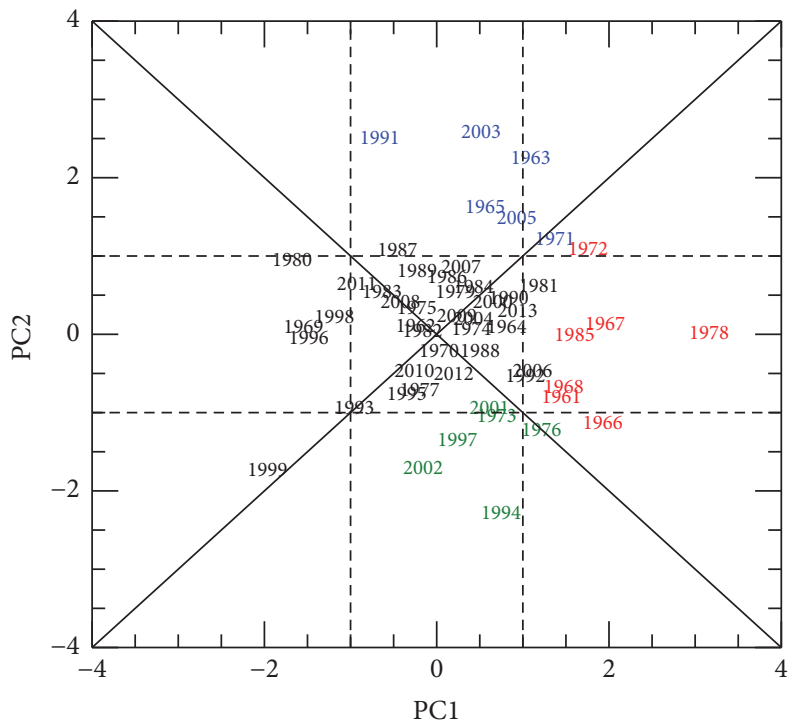

(d)

Figure 3: The normalized principal components (PCs): (a) PC1 and (b) PC2. (c) The moving $t$ test (MTT) of the first two PCs, in which red (black) solid line indicates MTT statistics of the PC1 (PC2) and dotted lines indicate 99\% confidence level. (d) The scatter diagram of the PC1 versus PC2 for 1961-2013, in which the WBWD, SDNF, and SFND years are colored in red, blue, and green, respectively. Red line in (a) denotes trend line of PC1, significant at 95\% confidence level for the Mann-Kendall trend test, and red lines in (b) denote mean value of 1961-1991, 1992-2002, and 2003-2013.

Since six of seven WBWD years happened before 1980, we selected the four strongest WBWD years only in the period 1961-1979.

Figure 4 compares the spatial distribution of the SPI3 for the selected typical drought years corresponding to the three summer drought patterns of the MLRYRB. Regionwide drought occurred over the whole MLRYRB in 1966, 1967,1972 , and 1978. In 1963, 1965, 1991, and 2003, drought occurred in the southern portion of the MLRYRB accompanied by flood in the northern portion of the MLRYRB. However, in 1973, 1976, 1994, and 2002, flood was prevalent in the southern portion of the MLRYRB with drought in the northern portion of the MLRYRB. In particular, the SPI3 distribution of the selected typical drought years can reflect the characteristics of the three summer drought patterns of the MLRYRB, indicating that the above- mentioned criteria are reasonable, though the intensity and spatial extension of drought show regional differences among the four typical drought years corresponding to the three summer drought patterns.
3.2. The Relationship between Summer Drought Patterns and Summer Atmospheric Circulation in the Two Periods. The summer precipitation along the MLRYRB is the product of the mei-yu front, which is quasi stationary and is a characteristic feature of interaction between warm, moist wind from the tropics and the dry, cold airflow originating from the north [55]. The northwestern edge of WPSH transports a large amount of water vapor into East Asia [56], and it is measured at level of $500 \mathrm{hPa}$. Moreover, the $200 \mathrm{hPa}$ GPH field can well capture the characteristics of meridional circulation in the mid-high latitudes. As a prominent component of the Asian summer monsoon system, the SAH can considerably affect the weather and climate over the AsianPacific region [57]. In the upper atmosphere, the eastward (westward) extension of the SAH has a close conjunction with an anomalous anticyclone (cyclone) circulation centered over subtropical Asia [58]. The SAH is defined at level of $200 \mathrm{hPa}$. In this section, the relationship between summer drought patterns and summer atmospheric circulation during 19611979 and 1980-2013 is analyzed in terms of correlation maps 
TABLE 1: The correlation coefficients of the first two principal components with the summer PDO and AMO for the different periods.

\begin{tabular}{lcccccc}
\hline & & PDO & & \multicolumn{2}{c}{ AMO } \\
& $1961-2013$ & $1961-1979$ & $1980-2013$ & $1961-2013$ & $1961-1979$ & -0.33 \\
\hline PC1 & $-0.27^{*}$ & -0.09 & -0.16 & $-0.34^{* *}$ & -0.12 \\
PC2 & -0.08 & -0.31 & 0.04 & 0.04 & -0.14 & 0.10 \\
\hline
\end{tabular}

${ }^{*} 90 \%$ confidence level; ${ }^{* *} 95 \%$ confidence level.

TABLE 2: The typical drought years of the three summer drought patterns of the MLRYRB.

\begin{tabular}{lcccc}
\hline Pattern & \multicolumn{4}{c}{ Year } \\
\hline $\begin{array}{l}\text { Whole basin-wide drought } \\
\text { (WBWD) }\end{array}$ & 1966 & 1967 & 1972 & 1978 \\
$\begin{array}{l}\text { Southern drought and northern } \\
\text { flood (SDNF) }\end{array}$ & 1963 & 1965 & 1991 & 2003 \\
$\begin{array}{l}\text { Southern flood and northern } \\
\text { drought (SFND) }\end{array}$ & 1973 & 1976 & 1994 & 2002 \\
\hline
\end{tabular}

between first two PCs of SPI3 and $500 \mathrm{hPa}$ and $200 \mathrm{hPa} \mathrm{GPH}$ fields.

Figure 5 shows the correlation maps between the first two PCs time series of coefficients and summer $500 \mathrm{hPa}$ GPH during 1961-1979 and 1980-2013, respectively. The correlation map between the PC1 time series of coefficients and summer $500 \mathrm{hPa}$ GPH during 1961-1979 shows significant negative correlations over the Sea of Okhotsk and western subtropical Pacific as well as positive correlations over the Yellow Sea, but the region of positive correlation coefficients is smaller compared to other two regions (Figure 5(a)). These suggest that the WBWD pattern is influenced by negative anomalies over the Sea of Okhotsk and positive anomalies over the Yellow Sea and the weaker than normal WPSH during 19611979. The correlation map between the PC2 time series of coefficients and summer $500 \mathrm{hPa}$ GPH during 1961-1979 presents a wave-like pattern in the correlation field over western coast of British Isles (significant negative correlations) and the Black Sea (significant positive correlations) and western central Asia (significant negative correlations), as well as significant positive correlations over northern coast of Russia (Figure 5(b)). The SDNF (SFND) pattern over the MLRYRB during 1961-1979 is closely associated with positive (negative) anomalies over northern coast of Russia and a wave train of $500 \mathrm{hPa} \mathrm{GPH}$ anomalies, with negative (positive) anomalies over western coast of British Isles and western central Asia $\left(70^{\circ} \mathrm{E}, 60^{\circ} \mathrm{N}\right)$ and positive (negative) anomalies over the Black Sea. During 1980-2013, the correlation map between the PC2 time series of coefficients and summer 500 hPa GPH also displays a wave-like structure, with positive correlations over eastern Iceland coast and the northern Urals and negative correlations over northern Europe. It also shows a wave-like pattern from south to north over eastern Asia, with positive correlations over southern China and northeastern Russia and negative correlations over northern China, implying that an anomalous anticyclone (cyclone) over southern China accompanied by an anomalous cyclone (anticyclone) over northern China is connected with the SDNF (SFND) pattern during 1980-2013.

For 1961-1979, the PC1 time series of coefficients is positively correlated with summer GPH field at $200 \mathrm{hPa}$ over northern China, significant at $90 \%$ confidence level (Figure 6(a)). The correlation map between PC2 and summer $200 \mathrm{hPa} \mathrm{GPH}$ is similar to the correlation map of 500 $\mathrm{hPa}$ GPH but the correlation coefficients over northern coast of Russia are smaller in the time period 1961-1979 (Figure 6(b)). For 1980-2013, the correlation map between PC2 and summer $200 \mathrm{hPa}$ GPH shows a wave-like pattern, with significant and positive correlations over Iceland and the northern Urals and negative correlations over northern Europe. It also presents a wave-like pattern over eastern Asia, with significant positive correlations over southern China and northeastern Russia and negative correlations over northern China (Figure 6(c)). The correlation maps between PCs and summer $200 \mathrm{hPa}$ GPH for the periods 1961-1979 and 1980-2013 are similar to their corresponding correlation maps of $500 \mathrm{hPa}$ GPH.

\section{Atmospheric Circulation Characteristics of the Three Summer Drought Patterns}

To better understand the connection between summer drought patterns of the MLRYRB and atmospheric circulation, the similarities of atmospheric circulation corresponding to the three summer drought patterns of the MLRYRB (shown in Table 2) during 1961-1979 and 1980-2013 are shown and discussed. Also, the atmospheric circulation differences corresponding to the three summer drought patterns between the periods 1961-1979 and 1980-2013 are presented.

4.1. The Whole Basin-Wide Drought (WBWD) Pattern. The summer $500 \mathrm{hPa} \mathrm{GPH}$ anomalies show a wave-like pattern from low to high latitudes over eastern Asia, with negative anomalies over the western subtropical Pacific and Sea of Okhotsk and positive anomalies shifted from eastern Japan to the northwestern Pacific, in four typical WBWD years (Figure 7). The wave train of $500 \mathrm{hPa}$ GPH anomalies is closely associated with the MLRYRB's WBWD pattern and is consistent with the wave-like pattern of correlation between PC1 and summer $500 \mathrm{hPa}$ GPH during 19611979 (Figure 5(a)). During the four typical WBWD years, the WPSH was weaker than normal and located further eastward, weakening the southerly water vapor transport from its northwestern flank to southern China. However, there was a center of negative anomalies over northern Russia in 1966 (Figure 7(a)) and a center of positive anomalies in 1967 (Figure 7(b)). Note also that there were obvious 


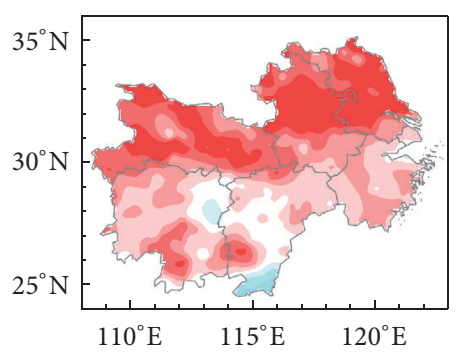

(a)

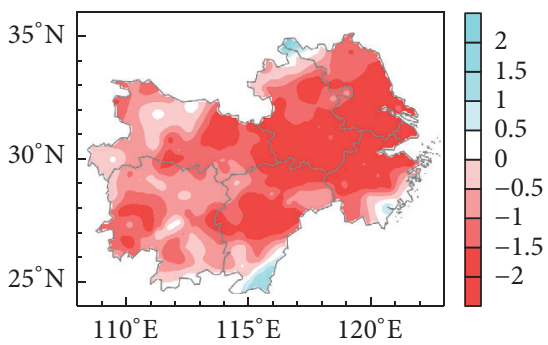

(d)

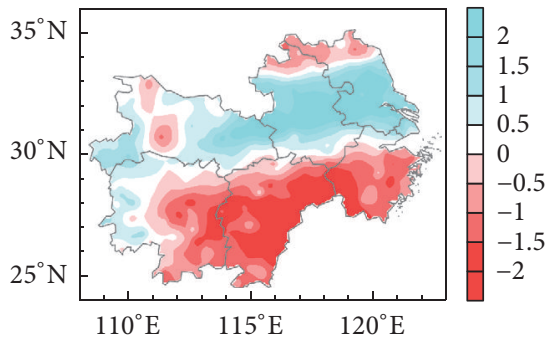

(g)

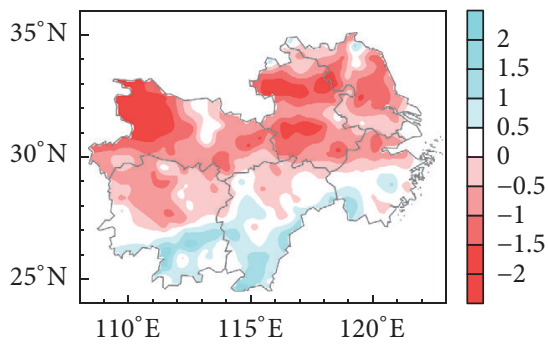

(j)

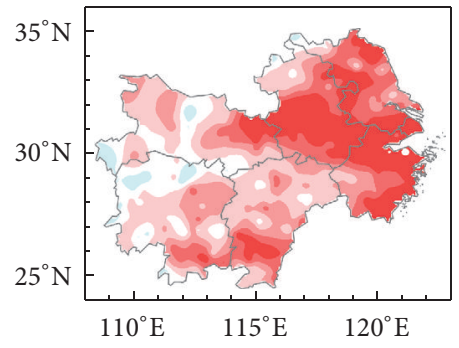

(b)

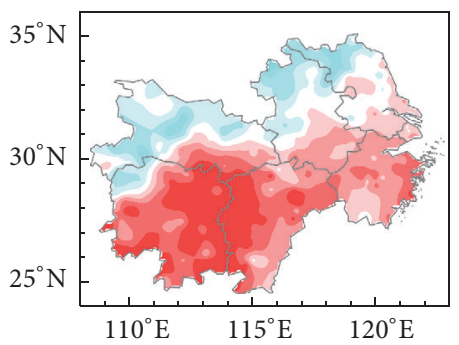

(e)

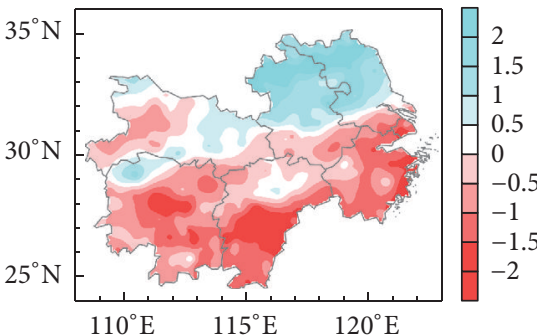

(h)

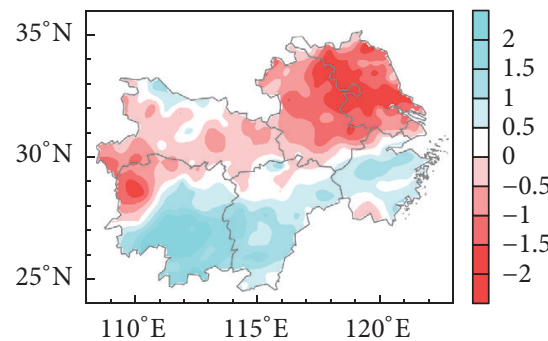

(k)

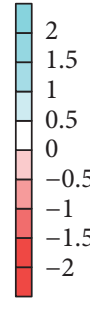

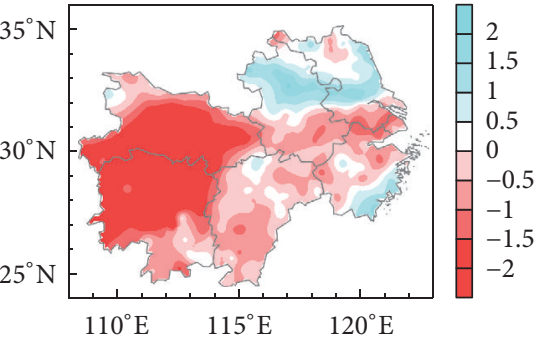

(c)

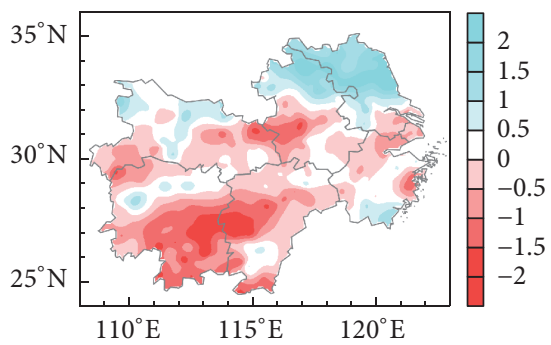

(f)

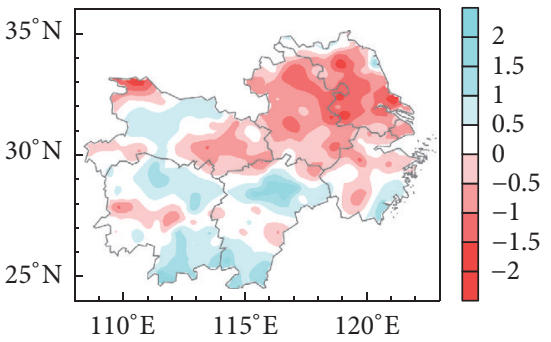

(i)

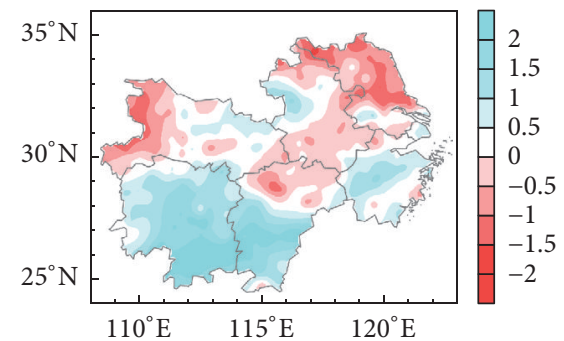

(l)

FIgURE 4: The distribution of the SPI3 for the typical drought years of the three drought patterns in the summers of (a) 1966, (b) 1967, (c) 1972, (d) 1978, (e) 1963, (f) 1965, (g) 1991, (h) 2003, (i) 1973, (j) 1976, (k) 1994, and (l) 2002. The positive values (blue) denote wet conditions, and the negative values (red) denote dry conditions.

positive anomalies over Europe in 1972 (Figure 7(c)) and negative anomalies centered over western Eurasia in 1978 (Figure 7(d)). These structural differences among four typical WBWD years may induce different drought intensity in the same subregion of the MLRYRB.

Figure 8 presents anomalies of vertically integrated water vapor transport for the typical drought years of the WBWD pattern. In 1966 (Figure 8(a)), the anomalous easterly water vapor transport expanded from the western tropical Pacific to Arabian Sea, resulting in below-normal southwesterly moisture transport from the Indian Ocean to eastern China. The anomalous southwesterly water vapor transport dominated the central and northeastern China. These events caused southerly water vapor transport deficit over the MLRYRB. In 1967 (Figure 8(b)), the southerly transport over eastern China was weakened as abundant moisture from the Indian Ocean was transported eastward to the western Pacific instead of northward to eastern China, which was associated with anomalous westerly transport over the western tropical Pacific. In 1972 (Figure 8(c)), the anomalous northeasterly water vapor transport dominated southeastern China and caused below-normal transport, because of an anomalous cyclonic moisture circulation along the coastline of eastern China and the abnormal westerly moisture transport from 


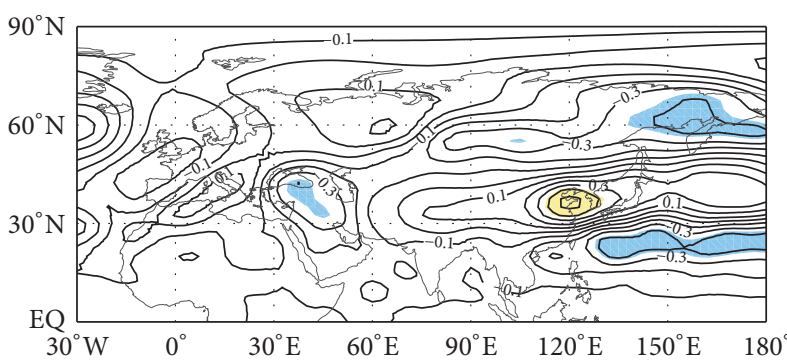

(a)

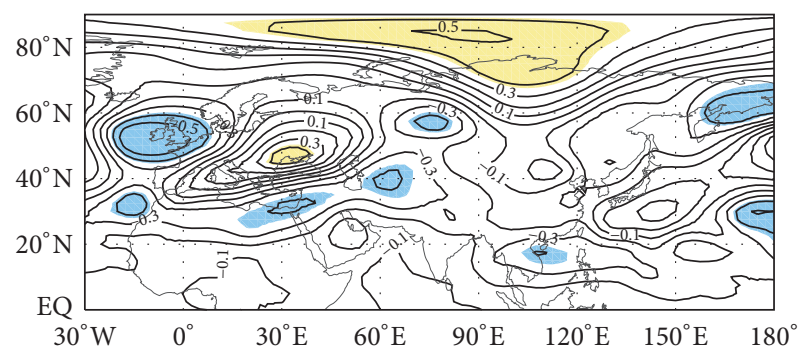

(b)

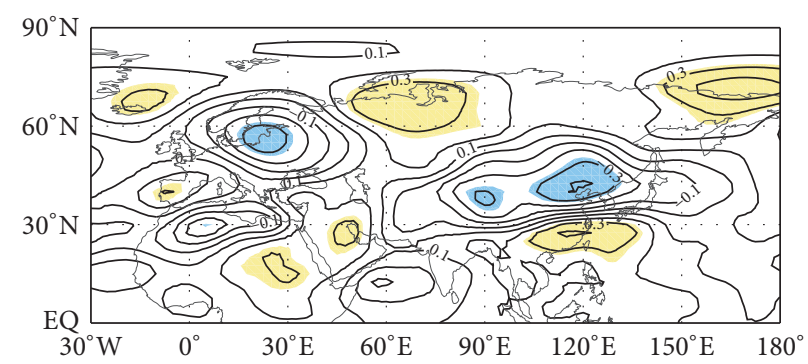

(c)

Figure 5: The correlation maps between PCs time series of coefficients and summer $500 \mathrm{hPa}$ geopotential height (GPH) for the periods 19611979 and 1980-2013. (a) PC1 for 1961-1979, (b) PC2 for 1961-1979, and (c) PC2 for 1980-2013. The shading (yellow for positive correlation and blue for negative correlation) exceeds $90 \%$ confidence level based on a two-tailed Student's $t$-test.

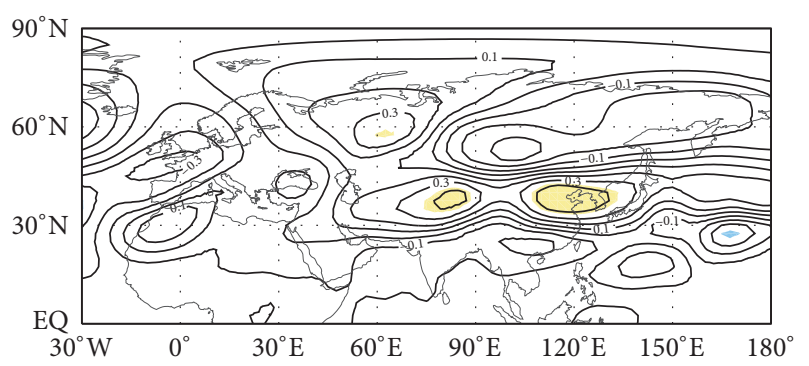

(a)

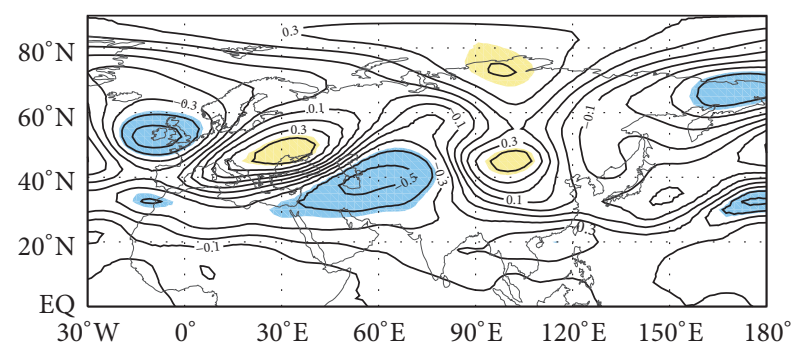

(b)

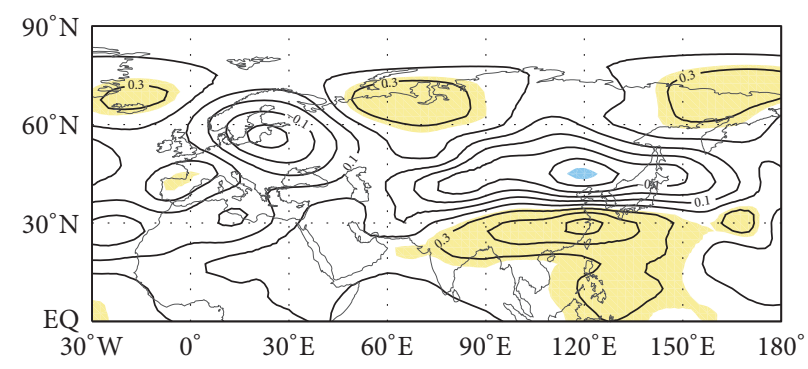

(c)

FIGURE 6: The correlation maps between PCs time series of coefficients and summer $200 \mathrm{hPa}$ GPH for the periods $1961-1979$ and $1980-2013$. (a) PC1 for 1961-1979, (b) PC2 for 1961-1979, and (c) PC2 for 1980-2013. The shading (yellow for positive correlation and blue for negative correlation) exceeds $90 \%$ confidence level based on a two-tailed Student's $t$-test.

the Bay of Bengal to tropical Pacific. In 1978 (Figure 8(d)), an anomalous cyclonic moisture circulation expanded from the western subtropical Pacific to the SCS, with an anomalous anticyclonic moisture circulation around $35^{\circ} \mathrm{N}$, resulting in water vapor deficit over the MLRYRB.

To investigate the influence of the upper-troposphere atmospheric circulation, especially the SAH, on the WBWD pattern, the SAH and summer GPH anomalies at $200 \mathrm{hPa}$ in the four typical WBWD years are analyzed. Figure 9 demonstrates a center of positive $200 \mathrm{hPa}$ GPH anomalies over northern China in the four typical WBWD years, suggesting that the SAH shifted slightly northward. The significantly positive correlations between $\mathrm{PCl}$ and summer $200 \mathrm{hPa} \mathrm{GPH}$ over northern China (Figure 6(a)) correspond to positive 


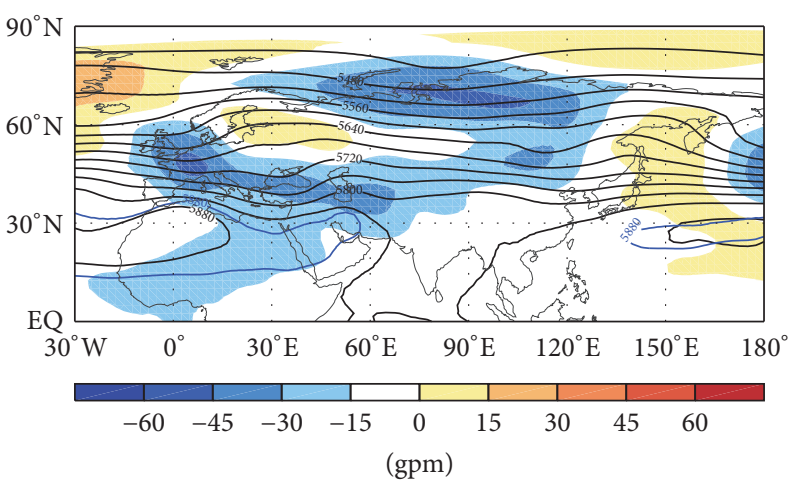

(a)

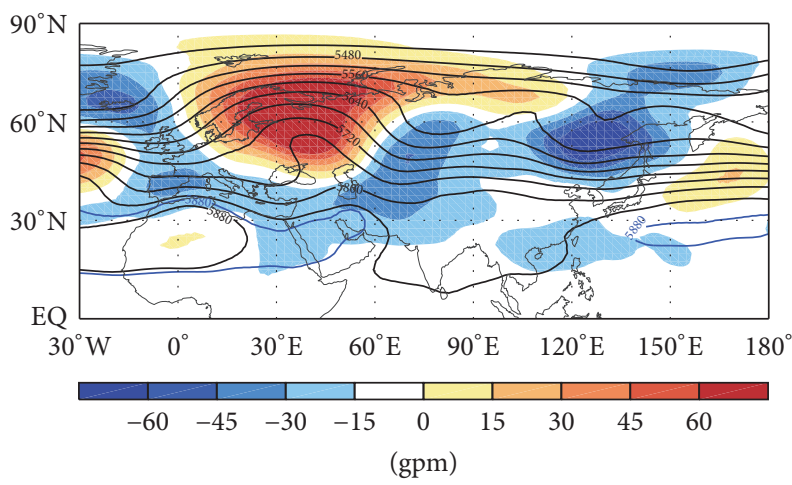

(c)

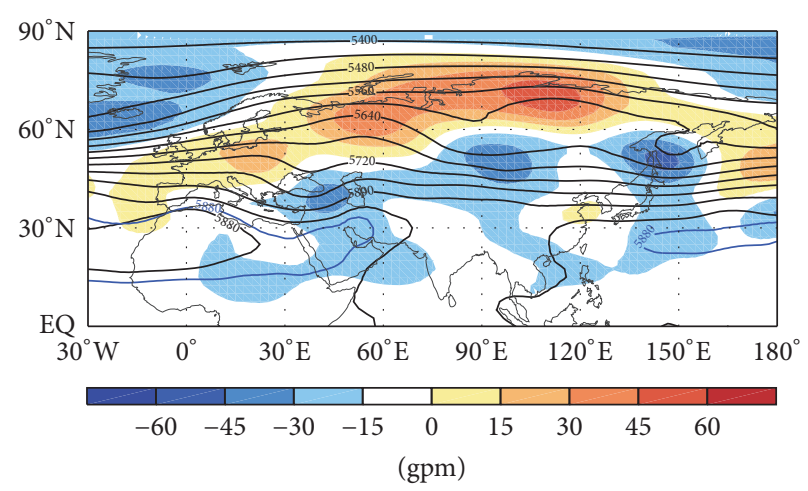

(b)

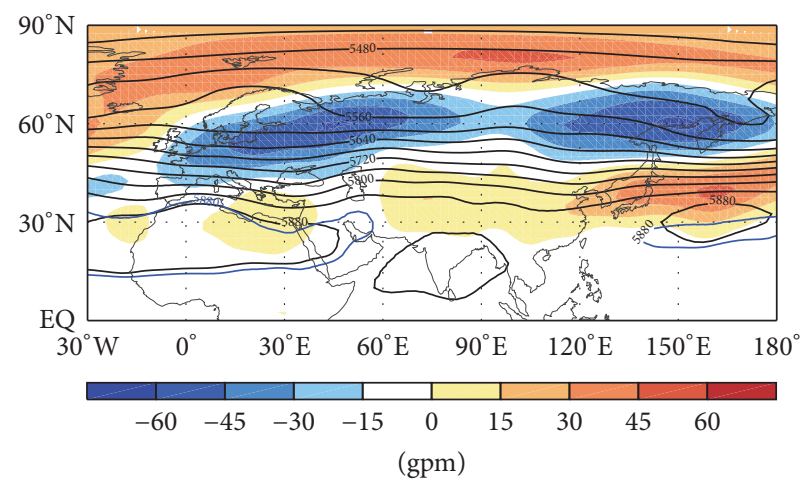

(d)

FIGURE 7: $500 \mathrm{hPa}$ GPH (contour) and its corresponding anomalies (shading) (units: gpm) of the WBWD pattern in the summers of (a) 1966, (b) 1967, (c) 1972, and (d) 1978; blue lines denote the climatology of $5880 \mathrm{gpm}$.

anomalies of summer $200 \mathrm{hPa}$ GPH in four typical WBWD years (Figure 9). Particularly, the eastern part of the SAH was abnormally weaker than normal and recessed westward in 1966 (Figure 9(a)), but it was stronger than normal and extended eastward in 1967 (Figure 9(b)). The SAH in 1972 was dramatically weaker than normal (Figure 9(c)), while in 1978 the SAH was stronger than normal and was spanning to westward (Figure 9(d)). Note that summer $200 \mathrm{hPa}$ GPH fields in the four typical WBWD years are similar to those corresponding to $500 \mathrm{hPa} \mathrm{GPH}$.

The water vapor transport is closely linked to atmospheric circulation change, and the East Asia summer monsoon is greatly controlled by the WPSH in the lower atmosphere [30]. For the WBWD pattern during 1961-1979, the WPSH was weaker and shifted eastward. This anomalous circulation pattern weakened water vapor transport from the SCS along the northwestern flank of the WPSH. In the upper atmosphere, the SAH shifted northward. The negative GPH anomalies over southern China indicated a stronger convergence there. This favored stronger divergence in the lower atmosphere, which was responsible for drought over the MLRYRB. It also should be emphasized that the southerly water vapor divergence results in whole basin drought. For the four typical WBWD years, the atmospheric circulation patterns at the $500 \mathrm{hPa}(200 \mathrm{hPa})$ level are dramatically similar over the regions where the correlation coefficients of the $\mathrm{PCl}$ and summer GPH field are significant in the period 1961-1979.
4.2. The Southern Drought and Northern Flood (SDNF) Pattern. Figures 10(a) and 10(b) show positive anomalies of summer GPH at $500 \mathrm{hPa}$ level over the North Pole and a large area of negative anomalies centered over British Isles and northwestern China/eastern Russia $\left(90^{\circ} \mathrm{E}, 45^{\circ} \mathrm{N}\right)$ which extended eastward over western Russia and eastern Asia, in 1963 and 1965, implying that the polar vortex was weaker than normal and the westerly circulation was straight. Therefore, the weaker than normal polar vortex and straight zonal circulation weakened the southward movement of the northerly cold flow in 1963 and 1965. Meanwhile, the WPSH was dramatically weaker than normal and situated further to the east. The atmospheric circulation patterns in 1963 and 1965 were similar in the regions of high correlations between PC2 and summer GPH at $500 \mathrm{hPa}$ during 19611979 (Figure 5(b)). Figures 10(c) and 10(d) show positive anomalies over the western Pacific and northeastern Russia and negative anomalies over the northwestern Pacific in 1991 and 2003. Furthermore, there was a wave train of $500 \mathrm{hPa}$ GPH anomalies characterized by positive anomalies centered over Greenland and northern Russia $\left(85^{\circ} \mathrm{E}, 60^{\circ} \mathrm{N}\right)$ and negative anomalies centered over western Russia $\left(40^{\circ} \mathrm{E}\right.$, $55^{\circ} \mathrm{N}$ ). However, the wave train of GPH anomalies at $500 \mathrm{hPa}$ in 1991 was dramatically weaker in comparison with 2003. The structural differences of $500 \mathrm{hPa}$ GPH anomalies between 1991 and 2003 may induce different intensity and location of drought in the MLRYRB. 


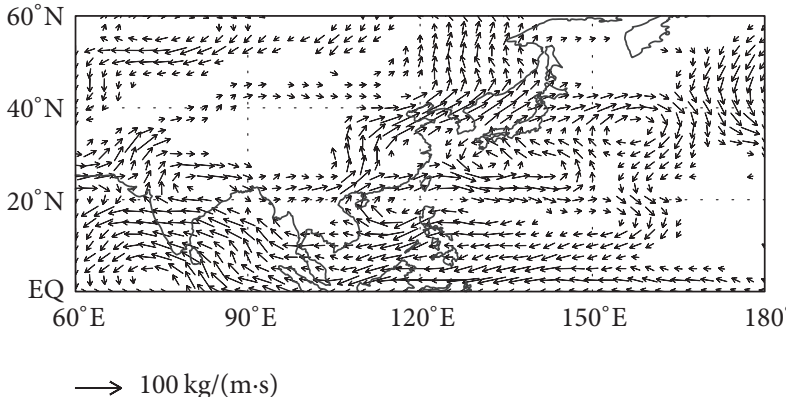

(a)

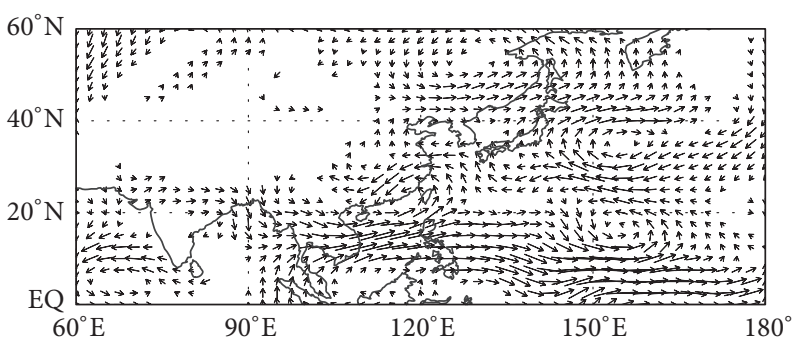

$\longrightarrow 100 \mathrm{~kg} /(\mathrm{m} \cdot \mathrm{s})$

(c)

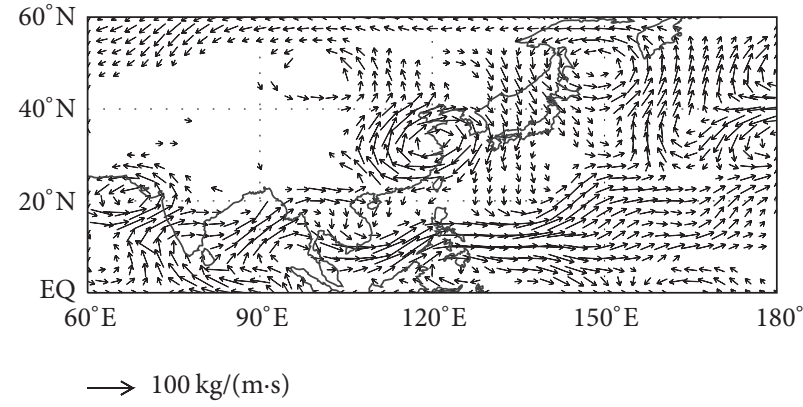

(b)

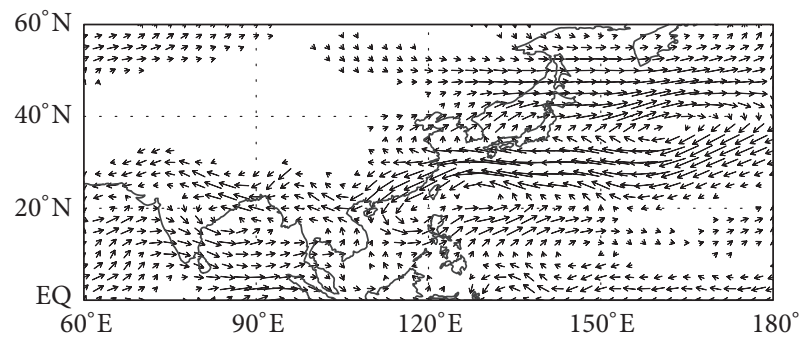

$\longrightarrow 100 \mathrm{~kg} /(\mathrm{m} \cdot \mathrm{s})$

FIGURE 8: Anomalies of vertically integrated water vapor flux (arrows, units: $\mathrm{kg} \mathrm{m}^{-1} \mathrm{~s}^{-1}$ ) of the WBWD pattern in the summers of (a) 1966, (b) 1967, (c) 1972, and (d) 1978.

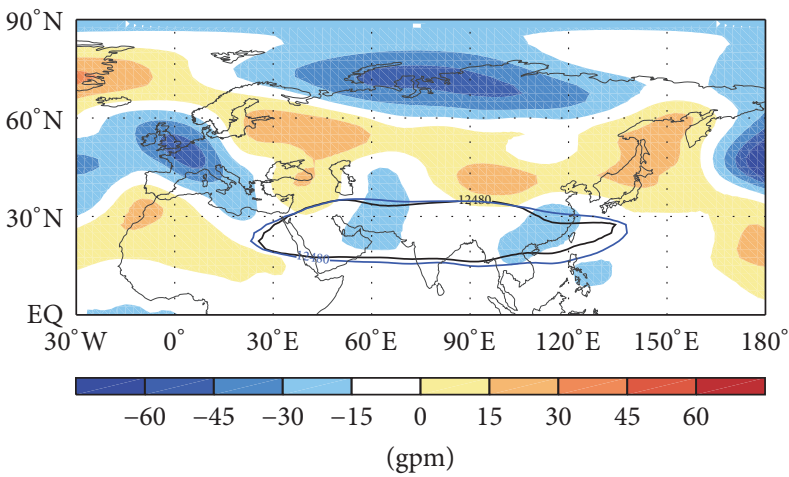

(a)

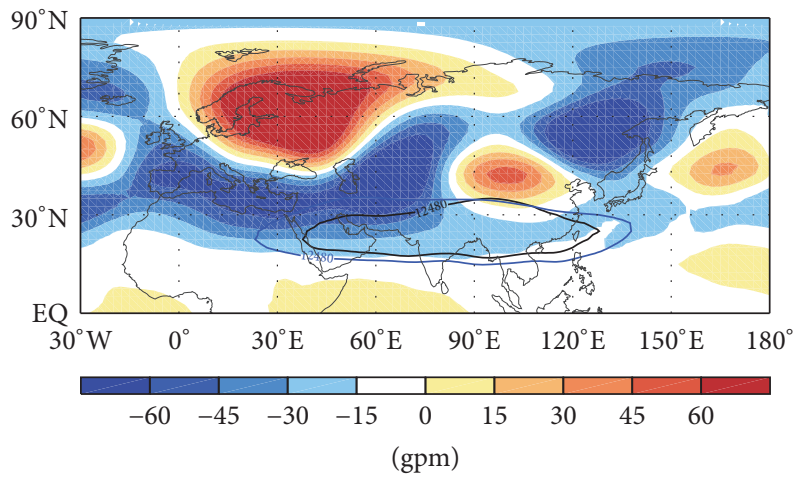

(c)

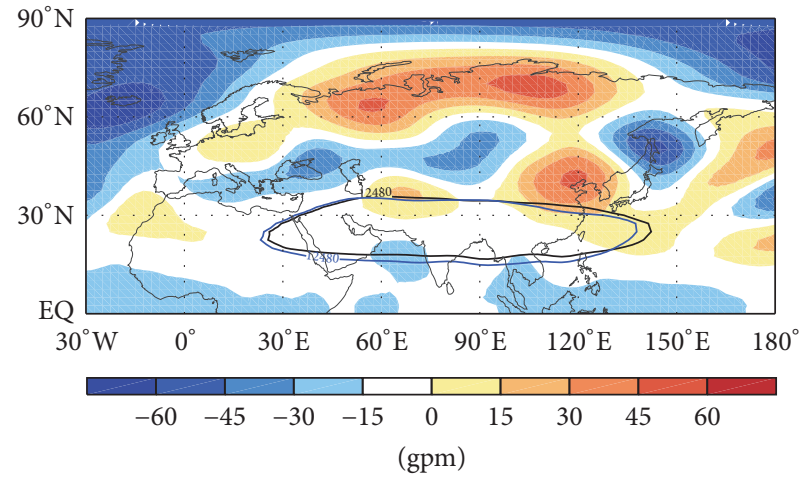

(b)

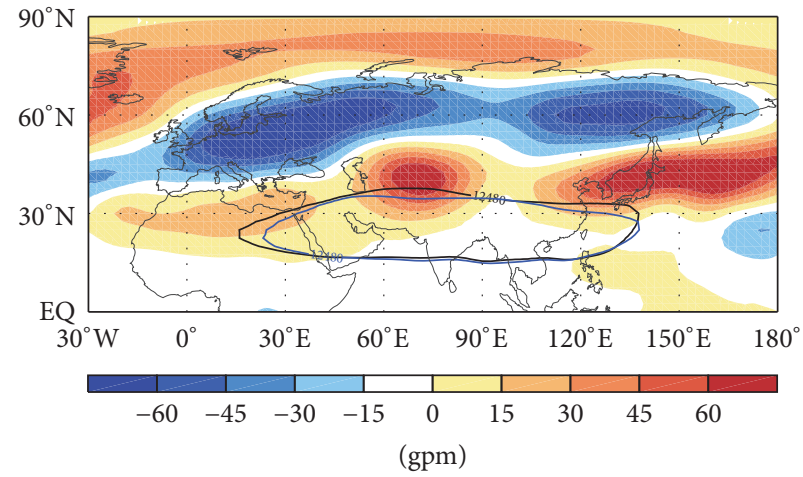

(d)

Figure 9: $200 \mathrm{hPa}$ GPH anomalies (shading) (units: gpm) of the WBWD pattern in the summers of (a) 1966, (b) 1967, (c) 1972, and (d) 1978; blue lines denote the climatology of $12480 \mathrm{gpm}$ and black lines indicate $12480 \mathrm{gpm}$ for the typical years. 


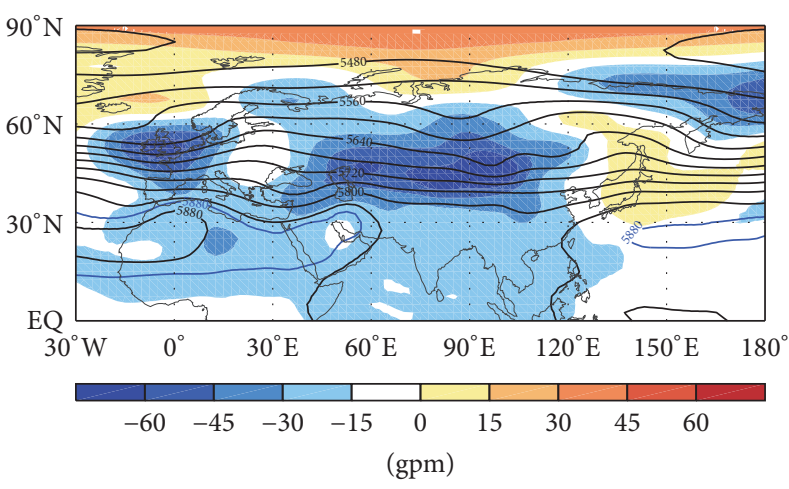

(a)

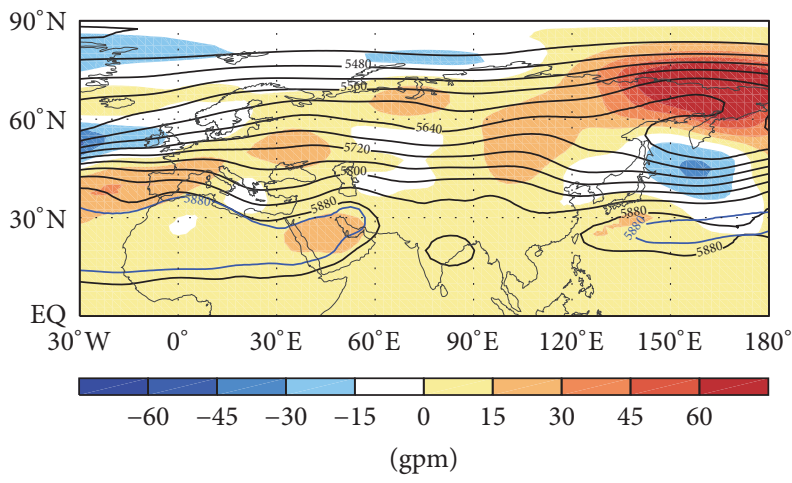

(c)

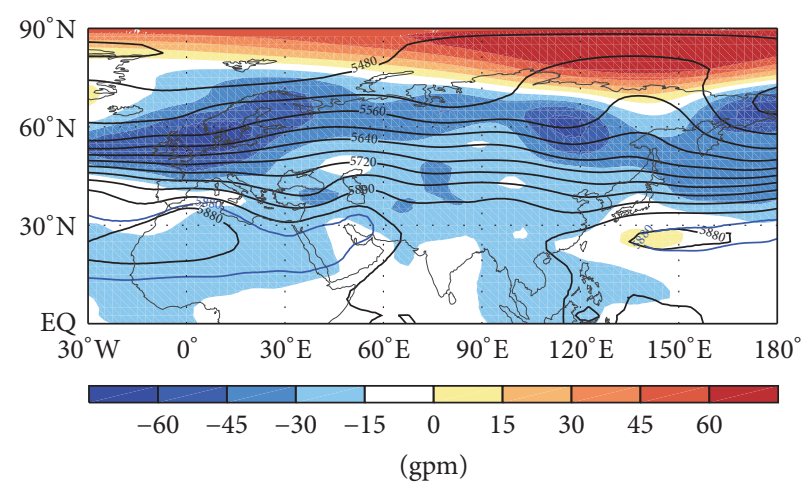

(b)

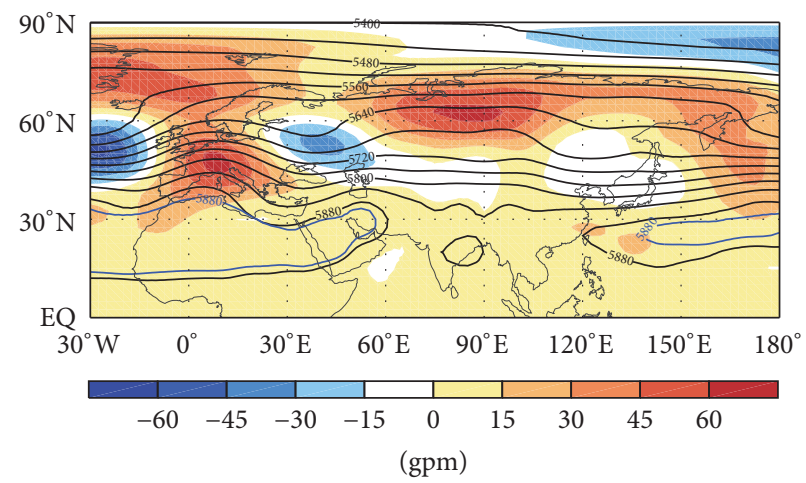

(d)

FIGURE 10: $500 \mathrm{hPa}$ GPH (contour) and its corresponding anomalies (shading) (units: gpm) of the SDNF pattern in the summers of (a) 1963, (b) 1965, (c) 1991, and (d) 2003; blue lines denote the climatology of $5880 \mathrm{gpm}$.

The anomalous anticyclonic circulation was developing in the coastline of East Asia in the four typical SDNF years (Figure 11). However, it shifted northeastward in 1963 and 1965, with respect to 1991 and 2003. In 1963 and 1965 (Figures 11(a) and 11(b)), this anomalous circulation benefited the northeastward water vapor transport from the western Pacific to Japan, weakening southerly water vapor transport over southern China. Further, the southerly water vapor transport was weakened when the water vapor from the Bay of Bengal was advected towards the western tropical Pacific, associated with anomalous westerly transport over the SCS and western tropical Pacific. This circulation pattern enhances the moisture deficit over southern China, including southern part of the MLRYRB. In 1991 and 2003 (Figures $11(\mathrm{c})$ and 11(d)), an anomalous anticyclonic circulation over the western Pacific extended westward to southeastern China, favoring northward moisture transport from the subtropical Pacific to northern China. Meanwhile, an anomalous cyclonic circulation centered over Japan benefited cold water vapor coming from high latitudes.

The SAH was abnormally weaker than normal in 1963 and 1965 (Figures 12(a) and 12(b)). A wave train pattern of summer $200 \mathrm{hPa}$ GPH anomalies characterized by negative anomalies over British Isles and central Asia and positive anomalies over southeastern Europe in 1963 was much stronger compared to 1965 . The circulation anomalies over the regions of high correlations between PC2 and summer
$200 \mathrm{hPa}$ GPH during 1961-1979 (Figure 6(b)) are similar to 1963 and 1965 . However, the SAH was dramatically stronger than normal, and there were positive anomalies over southern China and northeastern Russia and negative anomalies over northern China/eastern coast of Japan in 1991 and 2003 (Figures 12(c) and 12(d)). The summer $200 \mathrm{hPa}$ GPH anomalies patterns for 1991 and 2003 are widely similar, especially over the regions where the correlation coefficients between PC2 and summer 200 hPa GPH during 1980-2013 are significant.

For the SDNF pattern, the summer atmospheric circulation patterns for the selected typical years at the $500 \mathrm{hPa}(200 \mathrm{hPa})$ level are comparable for the periods 19611979 and 1980-2013, respectively. For 1963 and 1965, the straight westerly circulation and weakened polar vortex blocked the cold flow from the high latitudes, weakening southward expansion of cold flow from high latitudes to southern China. The WPSH was weaker than normal, which suppressed southerly moisture transport from the western Pacific to southern China. The warm water vapor from the SCS was transported to northern China, converging with the cold airflow over northern China, including the northern portion of the MLRYRB. In the upper atmosphere, the SAH was weaker than normal. The positive GPH anomalies at $200 \mathrm{hPa}$ level over northern China benefited anomalous divergence there, which was favorable for convergence in the lower atmosphere. This circulation pattern benefited 


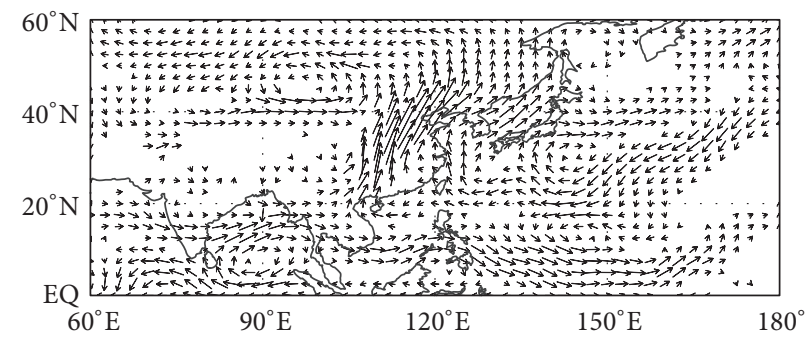

$\longrightarrow 100 \mathrm{~kg} /(\mathrm{m} \cdot \mathrm{s})$

(a)

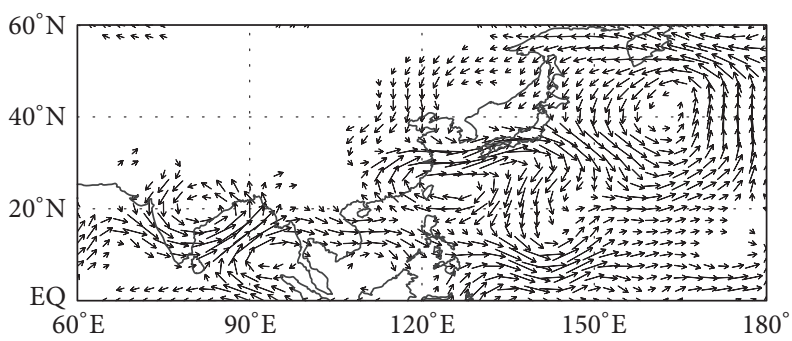

$\longrightarrow 100 \mathrm{~kg} /(\mathrm{m} \cdot \mathrm{s})$

(c)

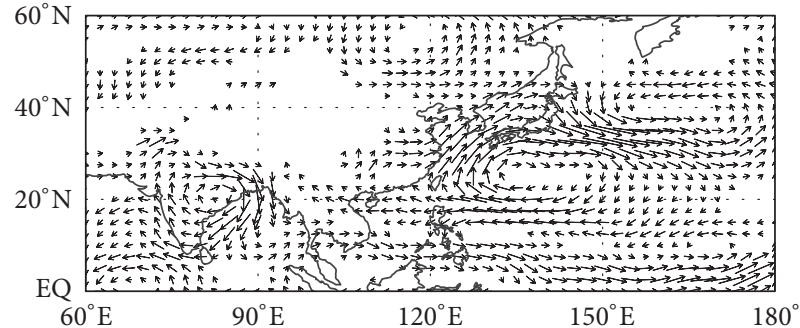

$\longrightarrow 100 \mathrm{~kg} /(\mathrm{m} \cdot \mathrm{s})$

(b)

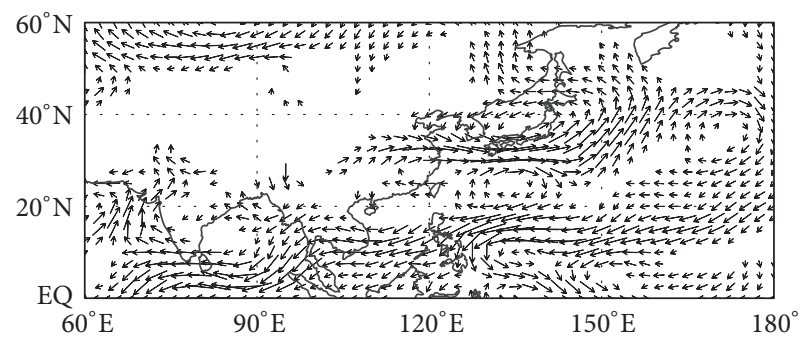

$\longrightarrow 100 \mathrm{~kg} /(\mathrm{m} \cdot \mathrm{s})$

(d)

FIGURE 11: Anomalies of vertically integrated water vapor flux (arrows, units: $\mathrm{kg} \mathrm{m}^{-1} \mathrm{~s}^{-1}$ ) of the SDNF pattern in the summers of (a) 1963, (b) 1965, (c) 1991, and (d) 2003.

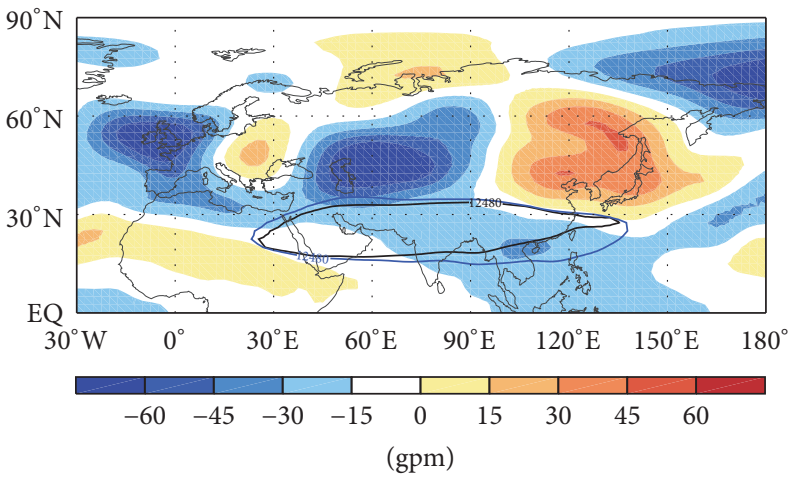

(a)

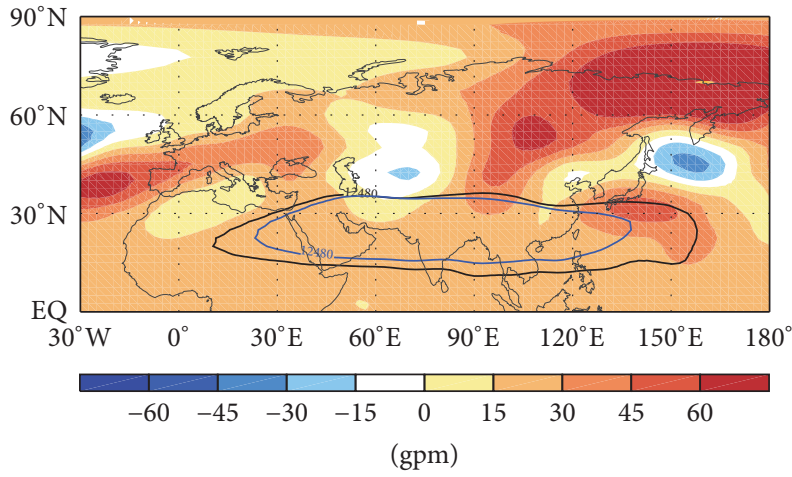

(c)

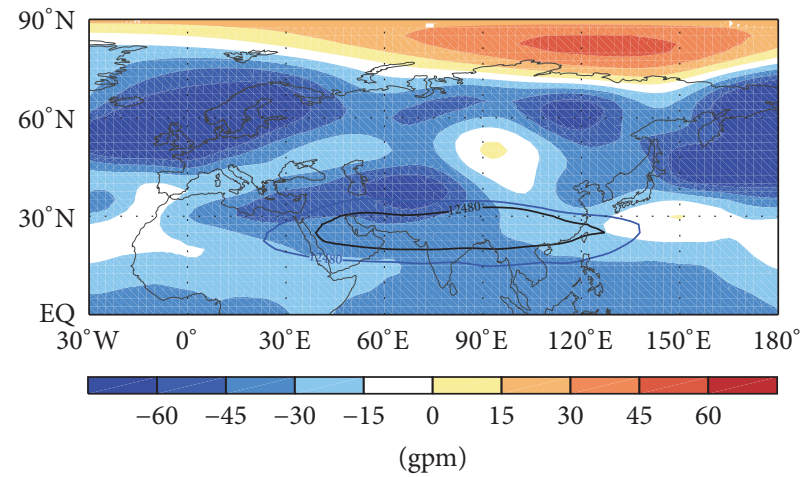

(b)

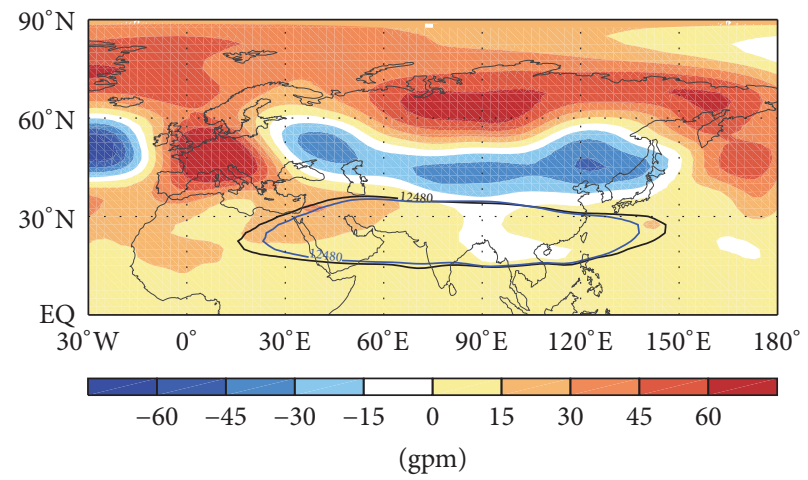

(d)

FIGURE 12: $200 \mathrm{hPa}$ GPH anomalies (shading) (units: gpm) of the SDNF pattern in the summers of (a) 1963, (b) 1965, (c) 1991, and (d) 2003; blue lines denote the climatology of $12480 \mathrm{gpm}$ and black lines indicate $12480 \mathrm{gpm}$ for the typical years. 
wet conditions in the northern part of the MLRYRB with dry conditions in the southern part. However, in the years 1991 and 2003, the eastern portion of the SAH extended eastward and the western portion of the WPSH extended westward, causing that the southern part of the MLRYRB was effectively under the influence of these enhanced high pressure systems. With the northwestward extension of the WPSH, the moisture from the western Pacific was transported to the northern part of the MLRYRB. Moreover, an anomalous cyclonic moisture circulation over Japan favored the southward expansion of the cold water vapor coming from high latitudes. The tropical water vapor converged with cold water vapor over northern part of the MLRYRB. Consequently, dry conditions were in the southern part of the MLRYRB with wet conditions in the northern part.

\subsection{The Southern Flood and Northern Drought (SFND) Pat-} tern. In 1973 and 1976 (Figures 13(a) and 13(b)), there was an obvious wave train of $500 \mathrm{hPa}$ GPH anomalies over the high latitudes, with two positive centers located over western coast of Europe and western central Asia and one negative center located over western Russia. The negative anomalies over northern coast of Russia suggested an increasing strength of the polar vortex, which impacted positively the southward propagation of cold flow. Meanwhile, the WPSH was located eastward, reducing the warm moisture transported by the WPSH from the western Pacific to eastern China. Note that summer $500 \mathrm{hPa}$ anomalies field in 1973 is similar to that in 1976, especially over the regions where the correlations between PC2 and summer $500 \mathrm{hPa}$ GPH are significant (Figure 5(b)). Figures 13(c) and 13(d) are characterized by two negative centers over eastern Greenland and the Ural mountains and one positive center over Europe. Moreover, the positive anomalies of $500 \mathrm{hPa}$ GPH were presented over northern China and negative anomalies over southern China in 1994 and 2002. Also, the atmospheric circulation field in 1994 is similar to that in 2002, especially over the regions of the high correlation coefficients between PC2 and summer $\mathrm{GPH}$ at $500 \mathrm{hPa}$ during 1980-2013 (Figure 5(c)).

Figure 14 presents anomalies of vertically integrated water vapor transport for the typical drought years of the SFND pattern. In 1973 and 1976 (Figures 14(a) and 14(b)), the anomalous southwesterly moisture transport from the SCS to southern China favored moisture convergence over the southern part of the MLRYRB. The anomalous tropical water vapor transport was divided into two branches, one in the Bay of Bengal and the other in the SCS. In 1973 (Figure 14(a)), an anomalous anticyclonic circulation was located in the coastline of northeastern China, with an anomalous northeasterly water vapor transport over eastern China. This water vapor transport was weaker and shifted eastward in 1976, compared to 1973. In 1994 (Figure 14(c)), an abnormal anticyclone was detected in the northeastern China, with anomalous northeasterly water vapor transport to southern China. Associated with abnormal southwesterly water vapor from the SCS to southern China, warm tropical moisture converged with cold flow over southern China, including southern part of the MLRYRB. In 2002 (Figure 14(d)), the anomalous northeasterly water vapor transport dominated eastern China and caused less than normal moisture transport from the SCS and Bay of Bengal to southern China. This circulation pattern benefited convergence over the southern part of the MLRYRB.

Figure 15 investigates the SAH and summer $200 \mathrm{hPa}$ GPH anomalies corresponding to the above-mentioned four typical SFND years. The SAH was basically weaker than normal in 1973 and 1976. A wave train of summer 200 $\mathrm{hPa} \mathrm{GPH}$ anomalies was characterized by positive anomalies over eastern coast of Europe and western central Asia and negative anomalies over western Russia. Specifically, negative anomalies occupied the northern coast of Russia in 1973 and 1976 (Figures 15(a) and 15(b)). In 1994 and 2002 (Figures 15(c) and 15(d)), there was a wave train characterized by a sequence of centers of positive and negative $200 \mathrm{hPa} \mathrm{GPH}$ anomalies: one center of positive anomalies over northern Europe and two centers of negative anomalies over eastern Iceland and the northern Urals, respectively. Moreover, a wave-like pattern of summer GPH anomalies at $200 \mathrm{hPa}$ covered eastern Asia, which is characterized by negative anomalies over southern China and northeast Russia and positive anomalies over northern China, although it was weaker in 2002 compared to 1994. The circulation patterns of summer $200 \mathrm{hPa}$ GPH in four typical SFND years are similar to their corresponding circulation patterns of summer $500 \mathrm{hPa}$ GPH, suggesting the presence of a barotropic vertical structure of the atmospheric circulation.

For the SFND pattern, the circulation patterns of the selected typical years are comparable for the same period. However, the crucial circulation features of the typical years during 1961-1979 are different from those during 1980-2013. For 1973 and 1976, a wave train over the high latitudes presented a barotropic vertical structure, which positively favored the southward propagation of the northerly cold flow. The WPSH was abnormally weaker compared to climatology, which weakened northward transport of southerly water vapor from the SCS and Bay of Bengal along the northwestern flank of the WPSH. Hence, southerly moisture converged with cold northerly flow over southern China, leading to wet conditions in the southern part of the MLRYRB accompanied by dry conditions in the northern part. For 1994 and 2002, a wave train characterized by two negative centers over eastern Greenland and the Urals and one positive center over Europe strengthened the southward propagation of the northerly cold flow, and the continental high pressure controlled northern China, which all were beneficial for drought over the northern part of the MLRYRB. The eastward recession of the WPSH caused below-normal water vapor transport from its northwestern flank to eastern China. The warm moisture converged with cold flow over southern China, resulting in more precipitation in the southern part of the MLRYRB.

\section{Conclusions and Discussion}

5.1. Conclusions. In this study, the spatiotemporal variability of summer drought as presented by SPI3 over the MLRYRB is extracted by EOF decomposition, and the summer drought of the MLRYRB is mainly featured by three patterns, including (i) dry conditions in the whole MLRYRB (referred to as 


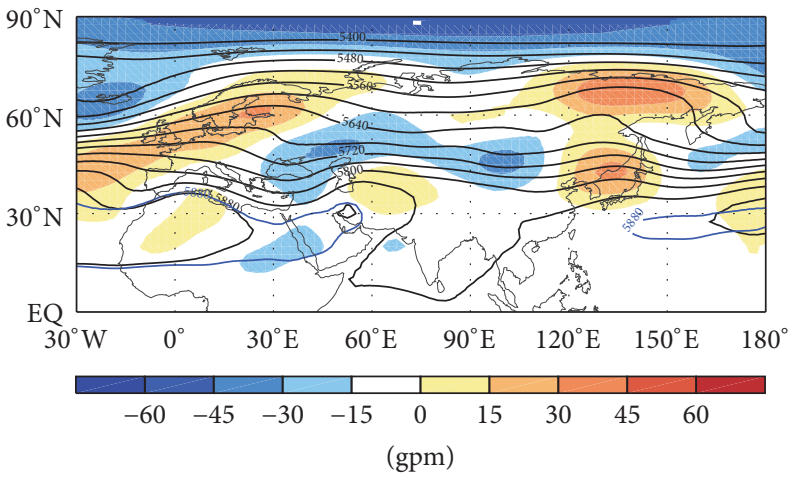

(a)

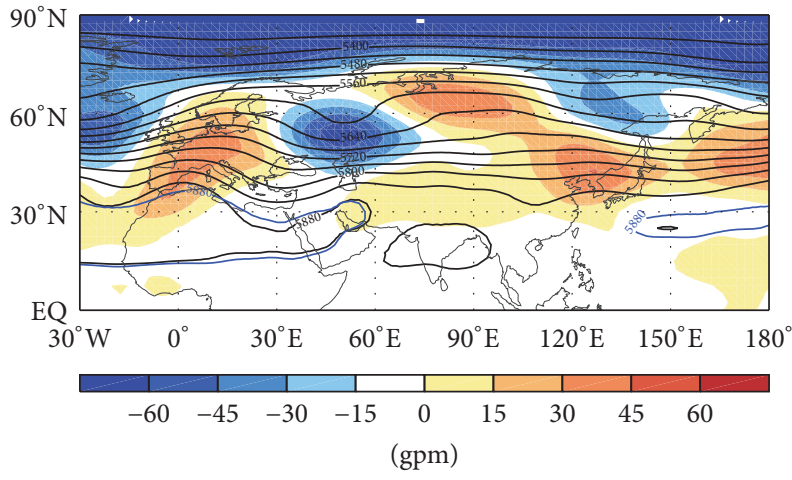

(c)

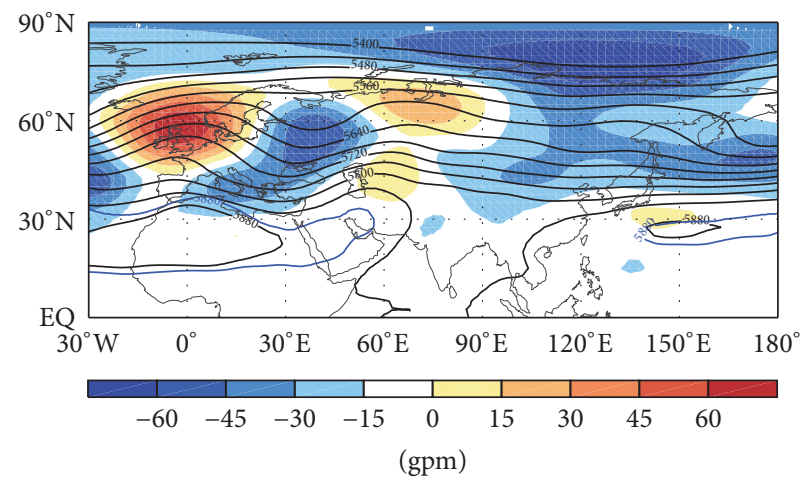

(b)

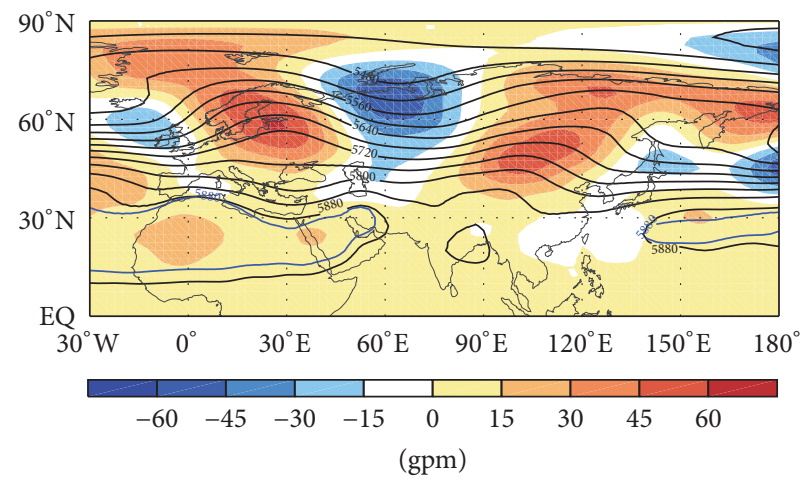

(d)

FIGURE 13: $500 \mathrm{hPa}$ GPH (contour) and its corresponding anomalies (shading) (units: gpm) of the SFND pattern in the summers of (a) 1973, (b) 1976, (c) 1994, and (d) 2002; blue lines denote the climatology of $5880 \mathrm{gpm}$.

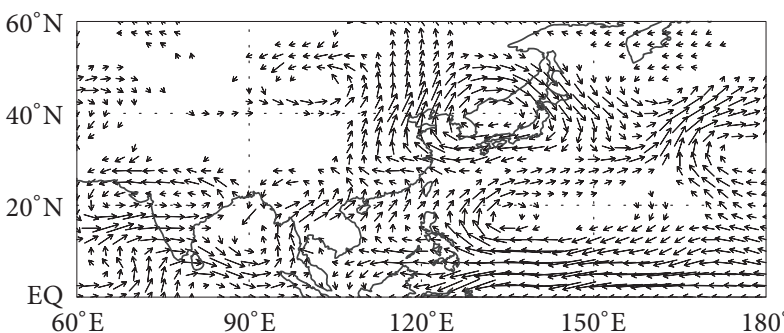

$\longrightarrow 100 \mathrm{~kg} /(\mathrm{m} \cdot \mathrm{s})$

(a)

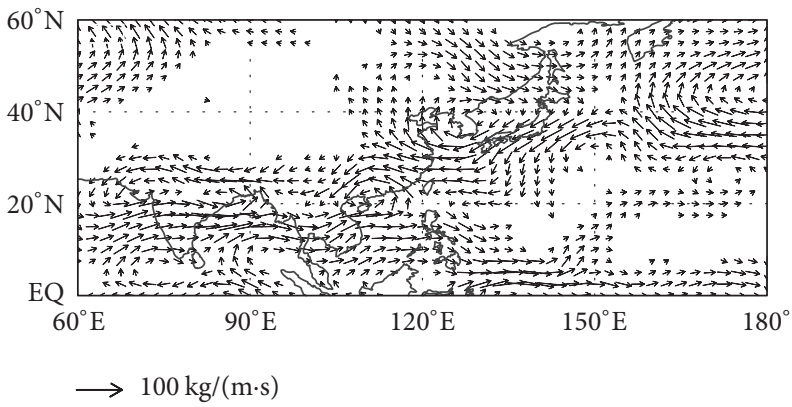

(c)

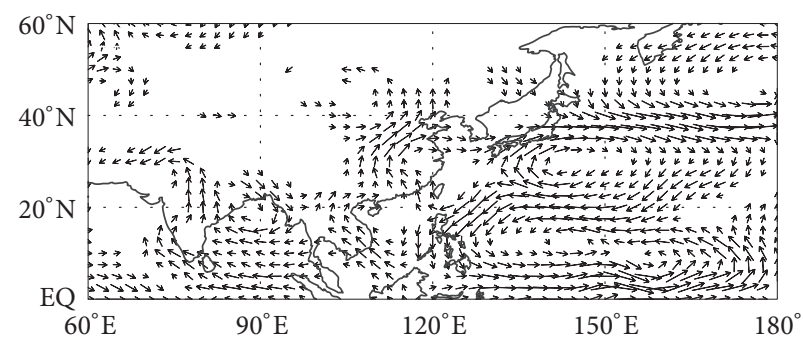

(b)

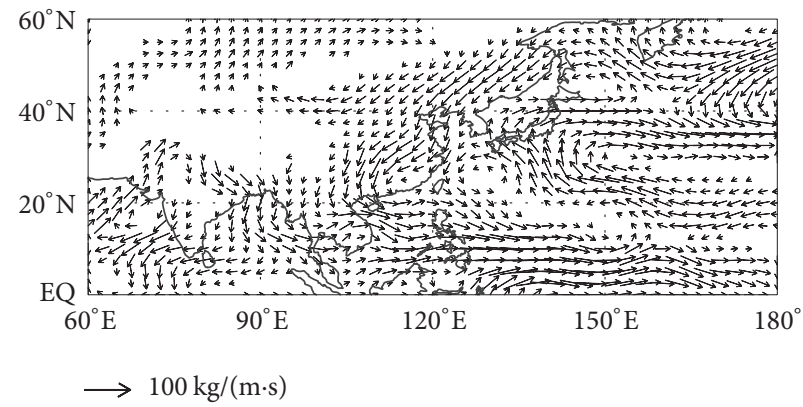

(d)

FIGURE 14: Anomalies of vertically integrated water vapor flux (arrows, units: $\mathrm{kg} \mathrm{m}^{-1} \mathrm{~s}^{-1}$ ) of the SFND pattern in the summers of (a) 1973, (b) 1976, (c) 1994, and (d) 2002. 


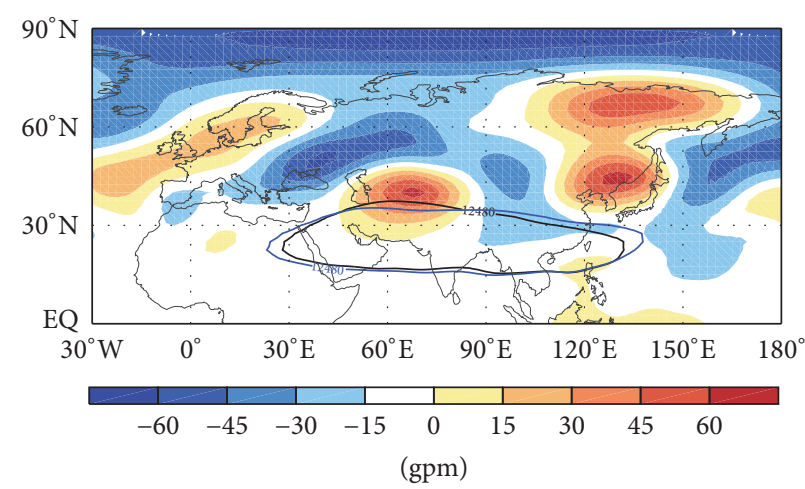

(a)

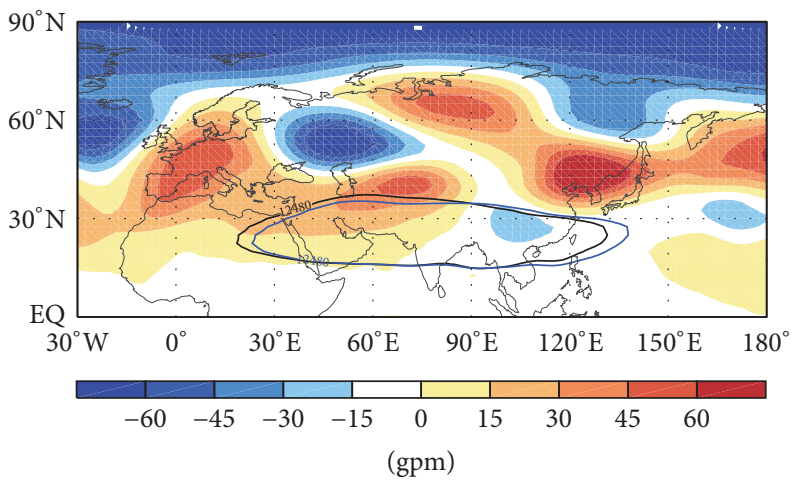

(c)

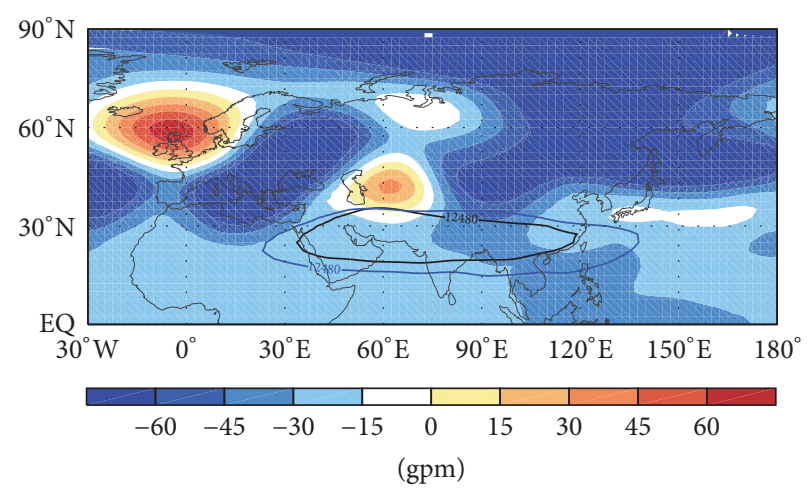

(b)

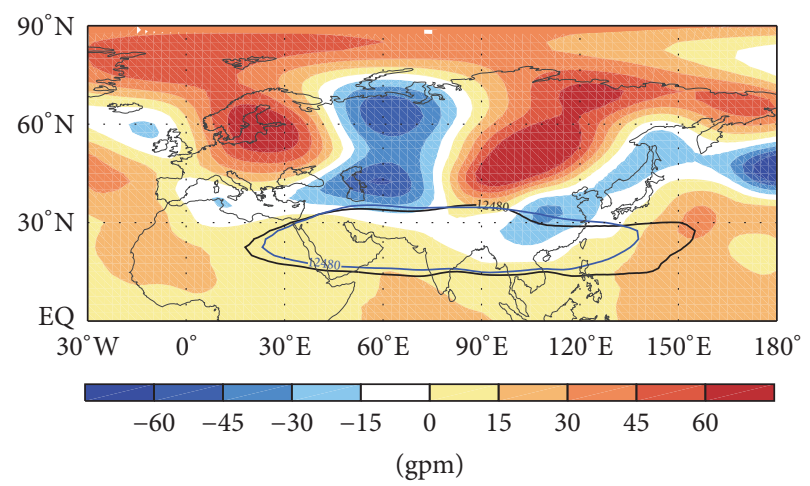

(d)

Figure 15: $200 \mathrm{hPa}$ GPH anomalies (shading) (units: gpm) of the SFND pattern in the summers of (a) 1973, (b) 1976, (c) 1994, and (d) 2002; blue lines denote the climatology of $12480 \mathrm{gpm}$ and black lines indicate $12480 \mathrm{gpm}$ for the typical years.

WBWD pattern), (ii) dry conditions in the southern part of the MLRYRB with wet conditions in the northern part (referred to as SDNF pattern), and (iii) wet conditions in the southern portion of the MLRYRB with dry conditions in the northern portion (referred to as SFND pattern). Furthermore, the atmospheric circulation fields corresponding to the three summer drought patterns for 1961-1979 are different from those for 1980-2013, suggesting that the climate shift in the late 1970s has led to different atmospheric internal mechanism of each summer drought pattern before and after 1980. Also, the similar results were obtained from the detrended GPH data (figures omitted).

For the WBWD pattern during 1961-1979, a meridional wave pattern of $500 \mathrm{hPa} \mathrm{GPH}$ anomalies presented over eastern Asia, with negative anomalies over the western subtropical Pacific and Sea of Okhotsk and positive anomalies shifted from Japan to the northwestern Pacific. The enhanced high ridge over Japan blocked the northerly cold flow from Siberia to southern China. The northward shift of the SAH also weakened cold flow from the high latitudes. Since the WPSH was apparently weaker than normal and located further eastward, the moisture transported from the western Pacific by subtropical high was abnormally deficient over southern China. This atmospheric circulation was not beneficial for precipitation, resulting in dry conditions over the whole MLRYRB.
For the SDNF pattern during 1961-1979, the straight westerly circulation and weakened polar vortex blocked the southward extension of the northerly cold flow. The weaker than normal WPSH suppressed the southerly moisture transport from the western Pacific to southern China. The anomalous southwesterly moisture transport from the SCS to northern China enhanced convergence in the middle latitudes, resulting in dry conditions in the southern part of the MLRYRB with wet conditions in the northern part. However, during 1980-2013, the eastward extension of the SAH and westward extension of WPSH impacted the southern part of the MLRYRB. Moreover, the northward extension of the WPSH enhanced the northward propagation of the southerly moisture, and an anomalous cyclonic circulation over northeastern China favored the southward expansion of the northerly cold flow. Consequently, dry conditions occurred in the southern part of the MLRYRB accompanied with wet conditions in the northern part.

For the SFND pattern during 1961-1979, an obvious wave train over the high latitudes presented the barotropic vertical structure, favoring that the northerly flow prevailed over southern China. An anomalous anticyclonic circulation along the coastline of northeastern China and the anomalous southwesterly moisture transport from the SCS to southern China benefited convergence over the southern part of the MLRYRB. The WPSH was weaker than normal, which 
weakened the northward transport of the southerly water vapor. This atmospheric circulation caused wet conditions in the southern part of the MLRYRB with dry conditions in the northern part. During 1980-2013, the continental high pressure controlled northern China, leading to drought in the northern part of the MLRYRB. The abnormal meridional circulation over the high latitudes favored the southward movement of the northerly cold flow. The WPSH recessed eastward, and the anomalous northeasterly moisture transport over eastern China converged with warm water vapor in the lower latitudes. This atmospheric circulation led to wet conditions in the southern part of the MLRYRB accompanied with dry conditions in the northern part.

5.2. Discussion. Surface weather conditions are directly governed by large-scale atmospheric circulation [59]. Swain et al. [60] indicated that the changes of atmospheric circulation have great influence on the extreme climate events in the Northern Hemisphere. In our study we investigated the changes of atmospheric circulation caused by climate shift in the late 1970s and highlighted the atmospheric circulation characteristics corresponding to the three summer drought patterns during 1961-1979 and 1980-2013. For the WBWD pattern during 1961-1979, the WPSH located eastward and was weaker than normal, which reduced the water vapor transport from its western flank to southern China. The WBWD pattern is closely associated with location and intensity of the WPSH. The WPSH is modulated by different types of El Niño-Southern Oscillation (ENSO) during the boreal summer [61], and the northward jump time of the WPSH is correlated with the Pacific Decadal Oscillation (PDO) on the interdecadal time scales [62]. Specifically, for the SDNF (SFND) pattern, the atmospheric internal mechanism for 1961-1979 is different from that for 1980-2013. This is a very important result, especially in the view of recent findings of Li et al. [63], who indicated that climate shift in the late 1970s leads to significant changes of the lowlevel atmospheric circulation which are closely linked to the summer precipitation in China on interdecadal time scales.

The summer drought over the MLRYRB is affected by multiple factors, such as atmospheric internal dynamics, the SST forcing, and land-atmospheric interaction [64-66]. However, it is widely considered that the most important predictability source originates from the SST forcing [67]. In fact, the SST forcing is directly linked to atmospheric circulation. Hu and Feng [68] investigated the interrelationship between Atlantic Multidecadal Oscillation (AMO) and ENSO and found that ENSO forcing can modify the atmospheric circulation variations driven by AMO in the midhigh latitudes. Also, the SST forcing can affect East Asian summer rainfall by modulating moisture transport associated with anomalous circulation [69]. Therefore, the relationship between the SST forcing and atmospheric circulation that affects the three summer drought patterns of the MLRYRB will deserve further exploring in the future.

\section{Competing Interests}

The authors declare that they have no competing interests.

\section{Acknowledgments}

The research is supported by National Natural Science Foundation of China (Grant nos. 41305056 and 41530531), National Basic Research Program of China (Grant no. 2012CB955901), and the key Special Scientific Research Fund of Meteorological Public Welfare Profession of China (Grant no. GYHY201506001).

\section{References}

[1] A. Dai, K. E. Trenberth, and T. Qian, "A global dataset of Palmer Drought Severity Index for 1870-2002: relationship with soil moisture and effects of surface warming," Journal of Hydrometeorology, vol. 5, no. 6, pp. 1117-1130, 2004.

[2] J. Huang, H. Yu, X. Guan, G. Wang, and R. Guo, "Accelerated dryland expansion under climate change," Nature Climate Change, vol. 6, no. 2, pp. 166-171, 2016.

[3] K. R. Briffa, G. van der Schrier, and P. D. Jones, "Wet and dry summers in Europe since 1750: evidence of increasing drought," International Journal of Climatology, vol. 29, no. 13, pp. 18941905, 2009.

[4] J. P. Huang, X. D. Guan, and F. Ji, "Enhanced cold-season warming in semi-arid regions," Atmospheric Chemistry and Physics, vol. 12, no. 12, pp. 5391-5398, 2012.

[5] S. Sherwood and Q. Fu, "A drier future?" Science, vol. 343, no. 6172, pp. 737-739, 2014.

[6] A. Dai, "Drought under global warming: a review," in Wirely Interdisciplinary Climate Change, vol. 3, pp. 45-65, 2010.

[7] J. P. Li, R. Swinbank, R. Q. Ding, and W. S. Duan, "Dynamics and predictability of high-impact weather and climate research," Bulletin of the American Meteorological Society, vol. 40, pp. 5497-5502, 2013.

[8] S. I. Seneviratne, "Climate science: historical drought trends revisited," Nature, vol. 491, no. 7424, pp. 338-339, 2012.

[9] J. Sheffield, E. F. Wood, and M. L. Roderick, "Little change in global drought over the past 60 years," Nature, vol. 491, no. 7424, pp. 435-438, 2012.

[10] J. Sheffield and E. F. Wood, "Projected changes in drought occurrence under future global warming from multi-model, multi-scenario, IPCC AR4 simulations," Climate Dynamics, vol. 31, no. 1, pp. 79-105, 2008.

[11] B. Orlowsky and S. I. Seneviratne, "Elusive drought: uncertainty in observed trends and short- and long-term CMIP5 projections," Hydrology and Earth System Sciences, vol. 17, no. 5, pp. 1765-1781, 2013.

[12] I. M. Held and B. J. Soden, "Robust responses of the hydrological cycle to global warming," Journal of Climate, vol. 19, no. 21, pp. 5686-5699, 2006.

[13] D. G. Kingston, J. H. Stagge, L. M. Tallaksen, and D. M. Hannah, "European-scale drought: understanding connections between atmospheric circulation and meteorological drought indices," Journal of Climate, vol. 28, no. 2, pp. 505-516, 2015.

[14] M. Ionita, G. Lohmann, N. Rimbu, S. Chelcea, and M. Dima, "Interannual to decadal summer drought variability over Europe and its relationship to global sea surface temperature," Climate Dynamics, vol. 38, no. 1-2, pp. 363-377, 2012.

[15] D. Jin, Z. Guan, and W. Tang, "The extreme drought event during winter-spring of 2011 in east China: combined influences of teleconnection in midhigh latitudes and thermal forcing in maritime continent region," Journal of Climate, vol. 26, no. 20, pp. 8210-8222, 2013. 
[16] M. Ionita, P. Scholz, and S. Chelcea, "Spatio-temporal variability of dryness/wetness in the Danube River Basin," Hydrological Processes, vol. 29, no. 20, pp. 4483-4497, 2015.

[17] T. Jiang, Z. W. Kundzewicz, and B. Su, "Changes in monthly precipitation and flood hazard in the Yangtze River Basin, China," International Journal of Climatology, vol. 28, no. 11, pp. 1471-1481, 2008.

[18] W. Hou, J. H. Zhao, and G. L. Feng, "Research about regional drought forecast criterion II: a method for the regional meteorological drought classification and its application to drought forecast," Plateau Meteorology, vol. 33, pp. 443-451, 2014 (Chinese).

[19] K. Xu, D. Yang, H. Yang, Z. Li, Y. Qin, and Y. Shen, "Spatiotemporal variation of drought in China during 1961-2012: a climatic perspective," Journal of Hydrology, vol. 526, pp. 253264, 2015.

[20] P. Zhai, X. Zhang, H. Wan, and X. Pan, "Trends in total precipitation and frequency of daily precipitation extremes over China," Journal of Climate, vol. 18, no. 7, pp. 1096-1108, 2005.

[21] C. Sun and S. Yang, "Persistent severe drought in southern China during winter-spring 2011: large-scale circulation patterns and possible impacting factors," Journal of Geophysical Research: Atmospheres, vol. 117, no. 10, pp. 63-74, 2012.

[22] A. J. Miller, D. R. Cayan, T. P. Barnett, N. E. Graham, and J. M. Oberhuber, "The 1976-77 climate shift of the Pacific Ocean," Oceanography, vol. 7, no. 1, pp. 21-26, 1994.

[23] B. Wang, "Interdecadal changes in El Niño onset in the last four decades," Journal of Climate, vol. 8, no. 2, pp. 267-285, 1995.

[24] D.-Y. Gong and C.-H. Ho, "Shift in the summer rainfall over the Yangtze River valley in the late 1970s," Geophysical Research Letters, vol. 29, no. 10, pp. 78-1-78-4, 2002.

[25] R. Yu and T. Zhou, "Seasonality and three-dimensional structure of interdecadal change in the East Asian monsoon," Journal of Climate, vol. 20, no. 21, pp. 5344-5355, 2007.

[26] L. Wang, Q. Huang, A. Dai, Z. Guan, J. He, and Z. Wu, "Inhomogeneous distributions of Meiyu rainfall in the Jiang-Huai basin, and associated circulation patterns," Climate Research, vol. 50, no. 2-3, pp. 203-214, 2011.

[27] M. H. Kwon, J.-G. Jhun, B. Wang, S.-I. An, and J.-S. Kug, "Decadal change in relationship between east Asian and WNP summer monsoons," Geophysical Research Letters, vol. 32, no. 16, Article ID L16709, 2005.

[28] L. Wang, W. Chen, W. Zhou, J. C. L. Chan, D. Barriopedro, and R. Huang, "Effect of the climate shift around mid 1970s on the relationship between wintertime Ural blocking circulation and East Asian climate," International Journal of Climatology, vol. 30, no. 1, pp. 153-158, 2010.

[29] M. Jacques-Coper and R. D. Garreaud, "Characterization of the 1970s climate shift in South America," International Journal of Climatology, vol. 35, no. 8, pp. 2164-2179, 2015.

[30] S. S. Huang and M. M. Tang, "On the structure of the summer monsoon regime of East Asia," Scientia Meteorologica Sinica, vol. 7, pp. 1-16, 1987 (Chinese).

[31] R. H. Huang and J. L. Chen, "Characteristics of the summertime water vapor transports over the eastern part of China and those over the western part of China and their difference," Chinese Journal of the Atmospheric Sciences, vol. 34, pp. 1035-1045, 2010 (Chinese).

[32] D. Z. Ye and B. Z. Zhu, Some Fundamental Problems of the General Circulation of the Atmosphere, Science Press, 1958, (Chinese).
[33] J. Mao, Z. Sun, and G. Wu, "20-50-Day oscillation of summer Yangtze rainfall in response to intraseasonal variations in the subtropical high over the western North Pacific and South China Sea," Climate Dynamics, vol. 34, no. 5, pp. 747-761, 2010.

[34] S. Matsumura, S. Sugimoto, and T. Sato, "Recent intensification of the western pacific subtropical high associated with the east Asian summer monsoon," Journal of Climate, vol. 28, no. 7, pp. 2873-2883, 2015.

[35] S. Y. Tao and S. Y. Xu, "Some aspects of the circulation during the periods of the persistent drought and flood in Yangtze and Huai-Ho valleys in summer," Acta Meteorologica Sinica, vol. 32, pp. 1-10, 1962 (Chinese).

[36] Y. Ding, Z. Wang, and Y. Sun, "Inter-decadal variation of the summer precipitation in East China and its association with decreasing Asian summer monsoon. Part I: observed evidences," International Journal of Climatology, vol. 28, no. 9, pp. 1139-1161, 2008.

[37] Q. Zhang, C.-Y. Xu, Z. Zhang, Y. D. Chen, C.-L. Liu, and H. Lin, "Spatial and temporal variability of precipitation maxima during 1960-2005 in the Yangtze River basin and possible association with large-scale circulation," Journal of Hydrology, vol. 353, no. 3-4, pp. 215-227, 2008.

[38] K. E. Trenberth and J. W. Hurrell, "Decadal atmosphere-ocean variations in the Pacific," Climate Dynamics, vol. 9, no. 6, pp. 303-319, 1994.

[39] Y. Zhang, T. Li, and B. Wang, "Decadal change of snow depth over the Tibetan Plateau in spring: the associated circulation and its relationship to the East Asian summer monsoon rainfal," Journal of Climate, vol. 17, pp. 2780-2793, 2004.

[40] Z. Lin, R. Lu, and W. Zhou, "Change in early-summer meridional teleconnection over the western North Pacific and East Asia around the late 1970s," International Journal of Climatology, vol. 30, no. 14, pp. 2195-2204, 2010.

[41] E. Kalnay, M. Kanamitsu, R. Kistler et al., "The NCEP/NCAR 40-year reanalysis project," Bulletin of the American Meteorological Society, vol. 77, no. 3, pp. 437-471, 1996.

[42] T. B. Mckee, N. J. Doesken, and J. Kleist, "The relationship of drought frequency and duration to time scales," in Proceedings of the 8th Conference on Applied Climatology, American Meteorological Socoiety, pp. 179-184, Anaheim, Calif, USA, January 1993.

[43] H.-R. Byun and D. A. Wilhite, "Objective quantification of drought severity and duration," Journal of Climate, vol. 12, no. 9, pp. 2747-2756, 1999.

[44] X. Lana, C. Serra, and A. Burgueño, "Patterns of monthly rainfall shortage and excess in terms of the standardized precipitation index for Catalonia (NE Spain)," International Journal of Climatology, vol. 21, no. 13, pp. 1669-1691, 2001.

[45] I. Bordi, K. Fraedrich, J.-M. Jiang, and A. Sutera, "Spatiotemporal variability of dry and wet periods in eastern China," Theoretical and Applied Climatology, vol. 79, no. 1-2, pp. 81-91, 2004.

[46] M. J. Hayes, M. D. Svoboda, D. A. Wilhite, and O. V. Vanyarkho, "Monitoring the 1996 drought using the Standardized Precipitation Index," Bulletin of the American Meteorological Society, vol. 80, no. 3, pp. 429-438, 1999.

[47] W. C. Palmer, Meteorological Drought, vol. 45 of Weather Bureau Research Paper, United States Department of Commerce, Washington, DC, USA, 1965.

[48] S. M. Vicente-Serrano, S. Beguería, and J. I. López-Moreno, "A multiscalar drought index sensitive to global warming: the 
standardized precipitation evapotranspiration index," Journal of Climate, vol. 23, no. 7, pp. 1696-1718, 2010.

[49] C. W. Thornthwaite, "An approach toward a rational classification of climate," Geographical Review, vol. 38, no. 1, pp. 55-94, 1948.

[50] D. S. Wilks, Statistical Methods in the Atmospheric Sciences, vol. 100 of International Geophysics Series, Academic Press, 2011.

[51] H. B. Mann, "Nonparametric tests against trend," Econometrica, vol. 13, pp. 245-259, 1945.

[52] M. G. Kendall, Rank Correlation Methods, Charles Griffin, London, UK, 4th edition, 1975.

[53] G. R. North, T. L. Bell, R. F. Cahalan, and F. J. Moeng, "Sampling errors in the estimation of empirical orthogonal functions," Monthly Weather Review, vol. 110, no. 7, pp. 699-706, 1982.

[54] C. Qian, J.-Y. Yu, and G. Chen, "Decadal summer drought frequency in China: the increasing influence of the Atlantic Multi-decadal Oscillation," Environmental Research Letters, vol. 9, no. 12, Article ID 124004, 2014.

[55] K.-M. Lau and M.-T. Li, "The monsoon of east Asia and its global associations-a survey," Bulletin of the American Meteorological Society, vol. 65, no. 2, pp. 116-125, 1984.

[56] T.-J. Zhou and R.-C. Yu, "Atmospheric water vapor transport associated with typical anomalous summer rainfall patterns in China," Journal of Geophysical Research D: Atmospheres, vol. 110, no. 8, pp. 1-10, 2005.

[57] P. Zhao, X. Zhang, Y. Li, and J. Chen, "Remotely modulated tropical-North Pacific ocean-atmosphere interactions by the South Asian high," Atmospheric Research, vol. 94, no. 1, pp. 4560, 2009.

[58] Y. Liu, B. J. Hoskins, and M. Blackburn, "Impact of Tibetan orography and heating on the summer flow over Asia," Journal of the Meteorological Society of Japan, vol. 85, pp. 1-19, 2007.

[59] J. A. Screen and I. Simmonds, "Amplified mid-latitude planetary waves favour particular regional weather extremes," Nature Climate Change, vol. 4, no. 8, pp. 704-709, 2014.

[60] D. L. Swain, D. E. Horton, D. Singh, and N. S. Diffenbaugh, "Trends in atmospheric patterns conducive to seasonal precipitation and temperature extremes in California," Science Advances, vol. 2, no. 4, Article ID e1501344, 2016.

[61] H. Paek, J.-Y. Yu, F. Zheng, and M.-M. Lu, "Impacts of ENSO diversity on the western Pacific and North Pacific subtropical highs during boreal summer," Climate Dynamics, 2016.

[62] T. Ye, Q. Shen, K. Wang, Z. Zhang, and J. Zhao, "Interdecadal change of the northward jump time of the western Pacific subtropical high in association with the Pacific Decadal Oscillation," Journal of Meteorological Research, vol. 29, no. 1, pp. 59-71, 2015.

[63] C. Li, T. Li, J. Liang, D. Gu, A. Lin, and B. Zheng, "Interdecadal variations of meridional winds in the South China Sea and their relationship with summer climate in China," Journal of Climate, vol. 23, no. 4, pp. 825-841, 2010.

[64] R. Lu, Y. Li, and B. Dong, "External and internal summer atmospheric variability in the western North Pacific and East Asia," Journal of the Meteorological Society of Japan, vol. 84, no. 3, pp. 447-462, 2006.

[65] A. Duan, G. Wu, Y. Liu, Y. Ma, and P. Zhao, "Weather and climate effects of the Tibetan Plateau," Advances in Atmospheric Sciences, vol. 29, no. 5, pp. 978-992, 2012.

[66] S. Wang, J. Huang, Y. He, and Y. Guan, "Combined effects of the Pacific Decadal Oscillation and El Niño-Southern Oscillation on global land dry-wet changes," Scientific Reports, vol. 4, article 6651, 2014.
[67] S.-Y. Yim, B. Wang, and W. Xing, "Prediction of early summer rainfall over South China by a physical-empirical model," Climate Dynamics, vol. 43, no. 7, pp. 1883-1891, 2014.

[68] Q. Hu and S. Feng, "AMO- and ENSO-driven summertime circulation and precipitation variations in North America," Journal of Climate, vol. 25, no. 19, pp. 6477-6495, 2012.

[69] X. Li, W. Zhou, D. Chen, C. Li, and J. Song, "Water vapor transport and moisture budget over eastern China: remote forcing from the two types of El Niño," Journal of Climate, vol. 27, no. 23, pp. 8778-8792, 2014. 

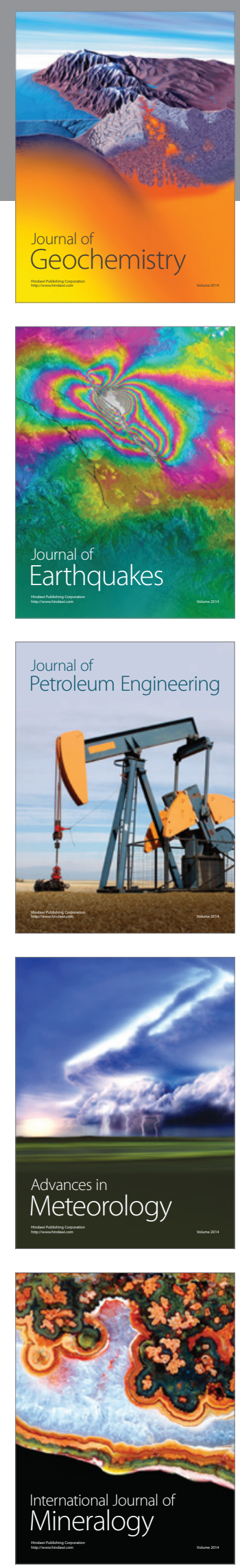
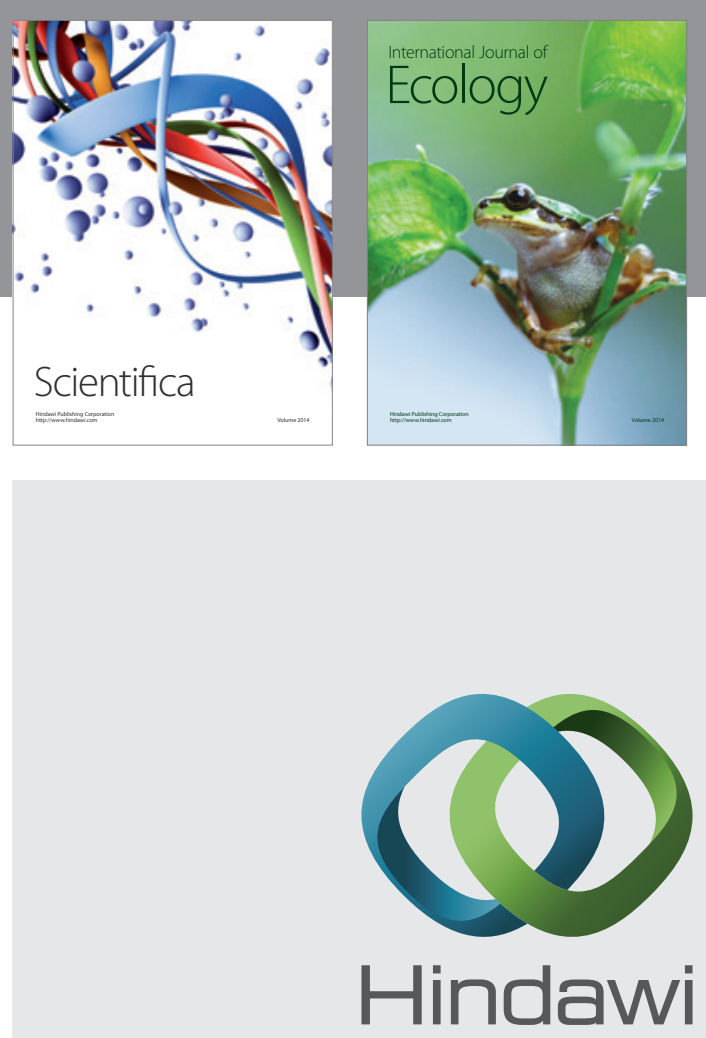

Submit your manuscripts at

http://www.hindawi.com
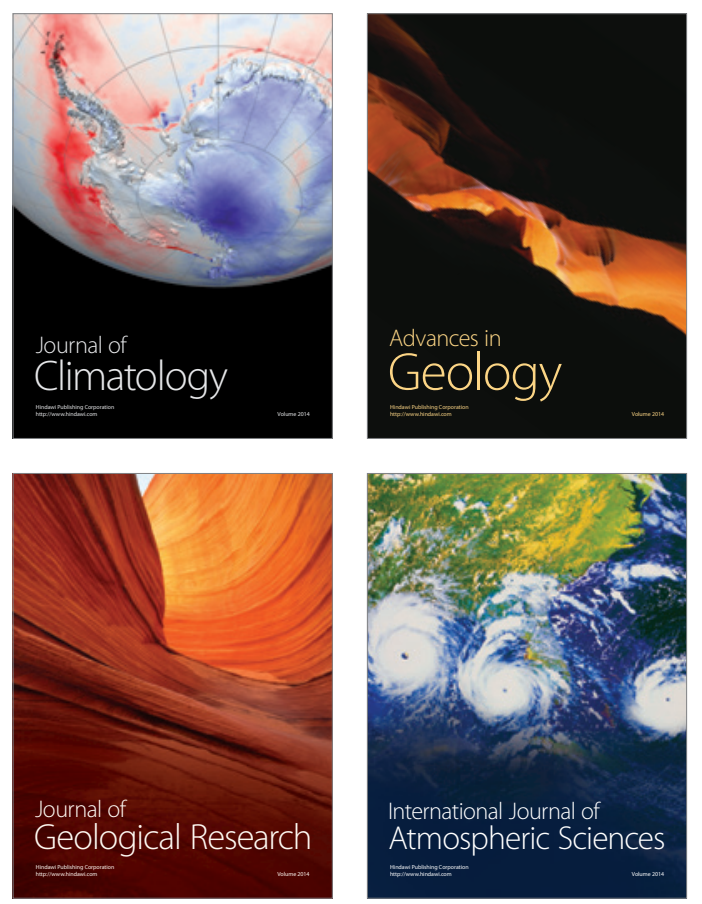

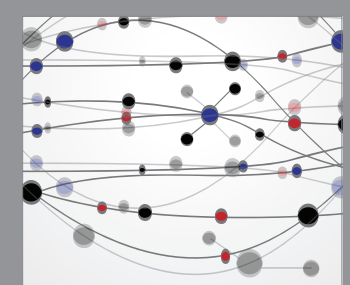

The Scientific

\section{World Journal}
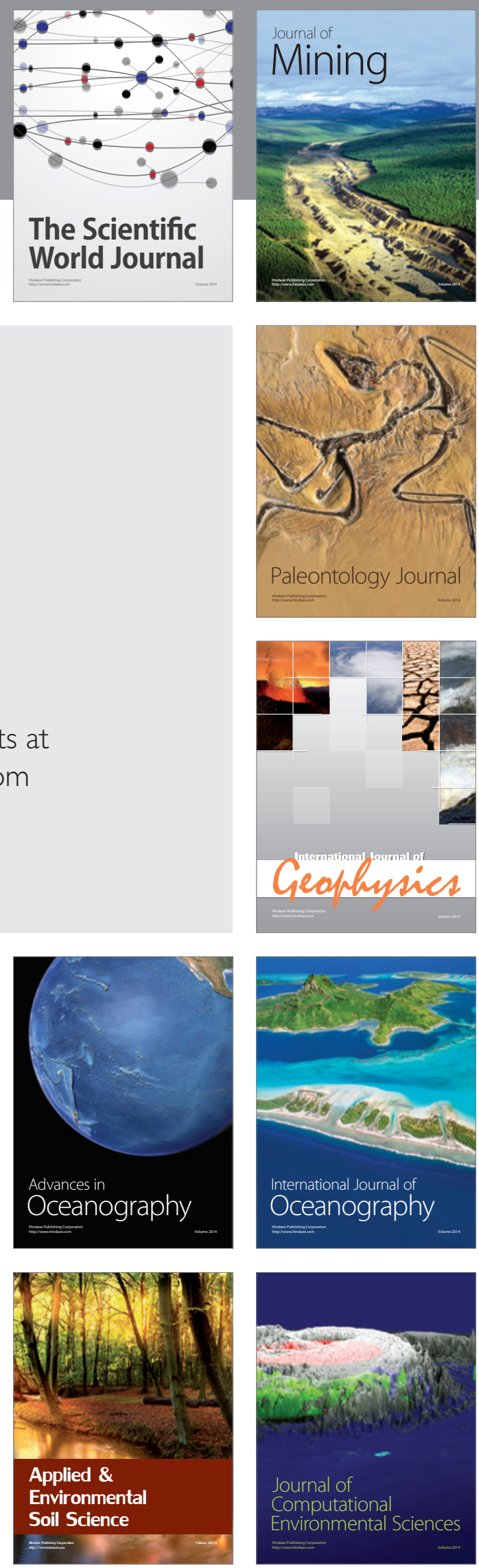